\title{
3. Direktinvestitionen und soziale Verantwortung der Unternehmen
}

Jürg Bärlocher, Bastienne Joerchel Anhorn and Peter Utting

\section{CpenEdition}

\section{Journals}

Electronic version

URL: http://journals.openedition.org/sjep/845

DOI: $10.4000 /$ sjep.845

ISSN: 1663-9677

\section{Publisher}

Institut de hautes études internationales et du développement

\section{Printed version}

Date of publication: 1 avril 2001

Number of pages: 105-153

ISSN: 1660-5926

\section{Electronic reference}

Jürg Bärlocher, Bastienne Joerchel Anhorn und Peter Utting, « 3. Direktinvestitionen und soziale Verantwortung der Unternehmen », Schweizerisches Jahrbuch für Entwicklungspolitik [Online], 20 | 2001, Online erschienen am: 03 September 2012, abgerufen am 08 September 2020. URL : http:// journals.openedition.org/sjep/845; DOI : https://doi.org/10.4000/sjep.845 


\title{
3. DIREKTINVESTITIONEN UND SOZIALE VERANTWORTUNG DER UNTERNEHMEN
}

\subsection{SCHWEIZERISCHE DIREKTINVESTITIONEN IN DEN TRANSFORMATIONS-, SCHWELLEN- UND ENTWICKLUNGSLÄNDERN}

\author{
JÜRG BÄRLOCHER*
}

\section{EINLEITUNG}

Direktinvestitionen und Entwicklungspolitik: Welches Datenmaterial steht für die Analyse dieses Themas zur Verfügung ? Dieser Beitrag befasst sich mit den Grundlagen der Direktinvestitionsstatistik. Zudem werden Ergebnisse für die Schweiz vorgestellt. Ausgangspunkt ist eine Beschreibung der Normen, welche von Internationalen Organisationen zur Harmonisierung der nationalen Direktinvestitionsdaten aufgestellt wurden. Anschliessend folgen einige Ausführungen zur Schweizer Statistik. Der Schlussabschnitt befasst sich mit den Ergebnissen für die Periode 1993-99, wobei das Schwergewicht bei den schweizerischen Investitionen in den Transformations-, Schwellen- und Entwicklungsländern liegt.

\section{GEGENSTAND DER DIREKTINVESTITIONSSTATISTIK}

Die schweizerische Direktinvestitionsstatistik orientiert sich am Balance of Payments Manual des IMF (BOPM) ${ }^{1}$ und der OECD Benchmark Definition of Foreign Direct Investment (Benchmark Definition). ${ }^{2}$ Das BOPM enthält Normen zur Erstellung der Zahlungsbilanz und der Statistik des Auslandsvermögens. Die Benchmark Definition übernimmt die im BOPM festgehaltenen Normen, führt aber genauer aus, wie Direktinvestitionsdaten erhoben werden sollen, um den internationalen Standards zu genügen.

In der Zahlungsbilanz erscheinen Direktinvestitionen als eine Komponente der Kapitalverkehrsbilanz, in welcher die Kapitaltransaktionen zwischen inländischen und ausländischen Wirtschaftssubjekten festgehalten werden. In der Statistik des Auslandsvermögens sind Direktinvestitionen ein Teil der Bestände der Forderungen und Verpflichtungen der inländischen gegenüber ausländischen Wirtschaftssubjekte. Zwei Aspekte sollen hier betont werden. Erstens sind Direktinvestitionen Investitionen im Sinne von Vermögensanlagen und deshalb von Investitionen im Sinne der Volkswirtschaftlichen Gesamtrechnung (Erhaltung oder Erweiterung des Produktionsapparates) zu unterscheiden. Zweitens können mit dem Begriff Direktinvestitionen sowohl Transaktionen als auch Bestände gemeint sein.

* Jürg Bärlocher: Wissenschaftlicher Mitarbeiter, Schweizerische Nationalbank (Abt. Zahlungsbilanz)

1. 5. Auflage, 1993.

2. 3. Auflage, 1996. 


\section{$\square$ Wann liegt eine Direktinvestitionsbeziehung vor?}

Gemäss BOPM und Benchmark Definition sind Direktinvestitionen internationale Investitionen, mittels derer ein dauerhafter Einfluss auf die Geschäftstätigkeit eines Unternehmens im Ausland ausgeübt werden soll. Zum Vergleich dazu: Bei der Kategorie Portfolioinvestitionen der Zahlungsbilanz und der Statistik des Auslandsvermögens steht die Erzielung einer angemessenen Rendite im Zentrum. Für die Statistik wird die Abgrenzung konkretisiert, es wird auf den Anteil des Investors am stimmberechtigten Kapital abgestellt. Die Normen des IMF und der OECD legen fest, dass eine Direktinvestitionsbeziehung vorliegt, wenn ein inländischer Investor $10 \%$ oder mehr des stimmberechtigten Kapitals eines Unternehmens im Ausland besitzt. In einem gewissen Ausmass ist die 10\%-Grenze arbiträr. Wichtig ist aber, dass Einfluss auf die Unternehmensführung nicht mit Kontrolle des Unternehmens (Stimmrechtsanteil von mehr als 50\%) gleichgesetzt wird.

\section{Welche Aggregate werden ausgewiesen?}

Laut den Vorgaben der Internationalen Organisationen umfassen die als Direktinvestitionen klassierten Kapitaltransaktionen sowohl die für das Entstehen einer Direktinvestitionsbeziehung grundlegende Transaktion als auch alle folgenden Kapitalflüsse zwischen Investor und Direktinvestitionsunternehmen. Dabei werden folgende Komponenten unterschieden:

- Erwerb und Veräusserung von Beteiligungskapital (einschliesslich Erwerb durch Aktientausch)

- Reinvestierte Erträge (einbehaltene Gewinne)

- Gewährung und Rückzahlung von Krediten (Konzernkredite)

Bei den reinvestierten Erträgen handelt es sich um fiktive Transaktionen. Die einbehaltenen Gewinne werden als Einkommen betrachtet, das an die Investoren ausbezahlt und unmittelbar wieder reinvestiert wird. In der Statistik der Kapitalbestände werden die reinvestierten Erträge zusammen mit dem Beteiligungskapital ausgewiesen.

\section{DIE SCHWEIZERISCHE DIREKTINVESTITIONSSTATISTIK}

Die Schweizerische Nationalbank erstellt seit Anfang der achtziger Jahre eine Direktinvestitionsstatistik. Vor 1993 bestand allerdings keine Auskunftspflicht. Dies beeinflusste die Statistik in zweierlei Hinsicht. Erstens war der Erhebungskreis unvollständig. Da alle in der Schweiz ansässigen Multinationalen Unternehmen sich von Beginn weg an der Erhebung beteiligten, beeinträchtigte dies allerdings die Datenqualität bei den Direktinvestitionen im Ausland weniger als bei den ausländischen Direktinvestitionen in der Schweiz. Zweitens war auf Verlangen einiger Meldefirmen der Detailierungsgrad der veröffentlichten Daten stark eingeschränkt. Mit dem 1993 in Kraft getretenen Bundesstatistikgesetz wurde eine obligatorische Auskunftspflicht für Unternehmen mit einem Direktinvestitionskapitalbestand von mehr als 10 Mio. Franken eingeführt. Durch die verbesserten Rechtsgrundlagen konnte der Erhebungskreis erweitert werden. Einschränkungen bei der Publikation ergeben sich seither nur noch aus Gründen des Datenschutzes, wonach die veröffentlichten Aggregate keine Rückschlüsse auf die Verhältnisse einzelner Unternehmen erlauben dürfen. 
Gehandhabt wird diese Weisung so, dass ein Aggregat dann publiziert wird, wenn es über einen längeren Zeitraum auf mindestens fünf Meldungen beruht und einzelne Investitionen nicht dominieren.

\section{$\square$ Kapitalflüsse und -bestände}

In der Direktinvestitionserhebung werden die Kapitalflüsse und -bestände in der im letzten Abschnitt erwähnten Gliederung in Beteiligungskapital, reinvestierte Erträge und Konzernkredite erfasst. Die Kapitalbestände beziehen sich auf Buchwerte. Die Benchmark Definition empfiehlt zwar generell Marktwerte als Bewertungsgrundlage, akzeptiert aber das aus Praktikabilitätsgründen in vielen Ländern angewandte Prinzip der Buchwerte bei den Kapitalbeständen.

\section{$\square$ Personalbestand}

Zusätzlich zum investierten Kapital wird der Personalbestand in den Direktinvestitionsunternehmen erhoben. Der Personalbestand ist dem Kapitalanteil entsprechend anzugeben. Ein Investor mit einem Kapitalanteil von 20\% an einem Unternehmen mit 1'000 Beschäftigten meldet also z.B. einen Personalbestand von 200 .

\section{$\square$ Ländergliederung}

Im Falle indirekter Beteiligungen, d.h. wenn ein Direktinvestor z.B. an einem Unternehmen 1 in Land A beteiligt ist, welches wiederum eine Beteiligung an einem Unternehmen 2 in Land B hält, stellt sich die Frage nach der Länderzuordnung der Investitionen. Soweit möglich, ist bei den Direktinvestitionen im Ausland das Prinzip des letztendlich wirtschaftlich begünstigten Unternehmens massgebend. Für die Kapitalbestände bedeutet dies im erwähnten Beispiel, dass der Teil des in Unternehmen 1 investierten Kapitals, der für die Finanzierung der Beteiligung an Unternehmen 2 eingesetzt wird, nicht Land A, sondern Land B zugeordnet wird. Analog dazu werden die reinvestierten Erträge demjenigen Land zugeordnet, in dem sie verbleiben. Bei den Flüssen auf dem Beteiligungskapital und den Krediten hingegen ist das Prinzip des letztendlich begünstigten Unternehmens nicht praktikabel. Genauer: Transaktionen zwischen Tochtergesellschaften werden nicht erfasst. Dadurch können Änderungen der länderweisen Kapitalbestände auftreten, für die kein korrespondierender Kapitalfluss ausgewiesen wird.

\section{$\square$ Sektoren- und Branchengliederung}

Die Sektoren- und Branchengliederung bezieht sich bei den Direktinvestitionen im Ausland auf die Haupttätigkeit des Investors in der Schweiz. Gewisse Interpretationsprobleme können daraus bei der Gruppe der Finanz- und Holdinggesellschaften entstehen. Direktinvestitionen von Konzernen mit Hauptsitz in der Schweiz fallen in der Regel nicht in diese Kategorie, auch wenn sie über eine Holdinggesellschaft gehalten werden, denn üblicherweise ist bei diesen Unternehmen das Halten von Beteiligungen nicht die Haupttätigkeit in der Schweiz. Mit dem Hauptzweck des Haltens von Auslandsbeteiligungen in der Schweiz vertreten sind aber verschiedene ausländische Konzerne. Dies hat zur Folge, dass in der Branchengruppe Finanz- und Holdinggesellschaften vor allem Direktinvestitionen ausländischer Konzerne ausgewiesen werden. 
Die Tabellen 1-3 (Seite 112 bis 120) enthalten Daten zu den schweizerischen Direktinvestitionen in den mittel- und osteuropäischen Transformations- und Entwicklungsländern (inkl. europäische GUS-Länder), den übrigen europäischen Entwicklungsländern und den Schwellen- und Entwicklungsländern in Asien, Mittel- und Südamerika sowie in Afrika. Diese Regionen umfassen die Länder, die im Rahmen des OECD-DAC-Programms finanziell unterstützt werden. Zusätzlich sind die Investitionen in den EU- und EFTA-Ländern sowie in den aussereuropäischen Industrieländern (USA, Kanada, Japan, Australien und Neuseeland) aufgeführt. Die Summe aller erwähnten Ländergruppen ergibt das Total der schweizerischen Direktinvestitionen im Ausland. ${ }^{3}$ Der Betrachtungszeitraum beginnt im Jahre 1993, weil - wie im dritten Abschnitt erwähnt - die Resultate der Direktinvestitionsstatistik erst seit dann in einer erweiterten Gliederung publiziert werden dürfen und die Ergebnisse vor 1993 bereits im 'Jahrbuch Schweiz-Dritte Welt 1993' vorgestellt wurden.

In Tabelle 1 sind die Kapitalexporte der Periode 1993-99 sowie der Kapitalund Personalbestand Ende 1999 aufgeführt. Neben den Ergebnissen für die Regionen sind in dieser Tabelle auch Länderergebnisse enthalten, wobei die Länderauswahl gemäss Höhe des Kapital- und Personalbestandes unter Berücksichtigung der für die Publikation erforderlichen Mindestzahl von Meldungen getroffen wurde. Während sich Tabelle 1 auf die Auslandsinvestitionen sämtlicher Unternehmen in der Schweiz bezieht, wird in Tabelle 2 nach Sektor des Investors unterschieden. In Tabelle 3 schliesslich wird zwischen Beteiligungskapital, reinvestierten Erträgen und Krediten differenziert.

Der Kapitalexport für schweizerische Direktinvestitionen im Ausland betrug im Jahre 199313 Mrd. Franken. Bis 1997 verdoppelte sich dieser Finanzfluss. Der Anteil der Transformations-, Schwellen- und Entwicklungsländer am gesamten Kapitalexport betrug in der Periode 1993-97 rund 15\%. Im Jahre 1998 wurde dann in den Industrieländern vorübergehend weniger investiert (Rückgang um 6 Mrd. auf 15 Mrd. Franken). Die Investitionen in den übrigen Regionen, vor allem in den asiatischen und lateinamerikanischen Schwellenländern sowie in den mittelamerikanischen Finanzzentren, wurden hingegen um $7 \mathrm{Mrd}$. auf 12 Mrd. Franken erhöht. Damit war 1998 rund 45\% des gesamten Kapitalexports für die Transformations-, Schwellen- und Entwicklungsländer bestimmt, eine Quote, die sich in der Folge allerdings wieder nach unten korrigierte. Die Kapitalflüsse in die Gebiete ausserhalb der Industrieländer nahmen zwar im Jahre 1999 um 1,5 Mrd. auf 13,5 Mrd. Franken zu, vermochten jedoch mit der markanten Steigerung der Investitionen in den Industrieländern von 15 Mrd. auf 41 Mrd. Franken nicht Schritt zu halten.

Die schweizerischen Direktinvestitionen im Ausland erreichten im Jahre 1999 einen Kapitalbestand von 308 Mrd. Franken. Davon entfiel ein Viertel auf Investitionen in den Transformations-, Schwellen- und Entwicklungsländern. Etwas höher lag der Anteil dieser Regionen bei den Arbeitsplätzen. Gut 30\% des gesamten Auslandspersonals war in Betrieben in den Transformations-, Schwellen- und Entwicklungsländern beschäftigt.

3. Berichte und ausführliche Tabellen zu den Direktinvestitionen werden jährlich im Quartalsheft der SNB (jeweils Nummer 4) publiziert. Ein Teil der Daten ist auch im Statistischen Monatsheft der SNB enthalten. Die Publikationen sind unter www.snb.ch verfügbar. 


\section{$\square$ Mittel- und Osteuropa}

In die mittel- und osteuropäischen Länder floss 1993-97 Direktinvestitionskapital von durchschnittlich 0.4 Mrd. Franken pro Jahr, hauptsächlich in der Form von Beteiligungskapital. In den Jahren 1998/99 betrugen die Kapitalexporte je gut 1 Mrd. Franken, wobei in diesem Zeitraum Konzernkredite und reinvestierte Erträge an Bedeutung gewannen.

Der Bestand der Direktinvestitionen in Mittel- und Osteuropa betrug Ende 1999 6,1 Mrd. Franken. Investoren aus der Industrie hielten rund 40\%, Investoren aus dem Dienstleistungssektor 35\%, Finanz- und Holdinggesellschaften $25 \%$ des Kapitals. $60 \%$ der 72'000 Arbeitsplätze entfielen auf die Auslandsbeteiligungen der Industrie.

Sowohl bezüglich Kapitalexport als auch bezüglich Kapital- und Personalbestand stechen Polen und die Tschechische Republik heraus. Ebenfalls ein bereits seit längerer Zeit bedeutender Direktinvestitionsstandort ist Ungarn. In Kroatien, Slowenien und auch in Bulgarien fand seit 1993 ein mässiger, aber kontinuierlicher Kapitalaufbau statt. Im Gegensatz dazu wurden in der Slowakei, den baltischen Staaten und in Rumänien erst seit 1997 einige grössere Investitionen getätigt. In der Russischen Föderation investierten Schweizer Unternehmen erheblich, besonders 1998/99. Von den übrigen europäischen GUS-Ländern verzeichnete die Ukraine seit 1997 einen gewissen Kapitalzufluss, während in Weissrussland und in Moldawien bisher noch keine grösseren Investitionen vorgenommen wurden.

\section{$\square$ Übrige europäische Entwicklungsländer}

In dieser Ländergruppe sind vor allem Direktinvestitionen in der Türkei sowie in Zypern und Gibraltar von Bedeutung. Beschäftigungsmässig ist die Türkei mit rund 10'000 Arbeitsplätzen - zu etwa gleichen Teilen in Unternehmen der Industrie und des Dienstleistungssektors - der wichtigste Direktinvestitionsstandort. Nach einem zuvor recht kontinuierlichen Kapitalaufbau erfolgte 1998 ein aussergewöhnlich grosser Kapitalexport in dieses Land. Im Jahre 1999 wurde dann Kapital aus der Türkei abgezogen. Für die Ländergruppe insgesamt resultierte dagegen 1998 ein Kapitalrückzug und 1999 ein Kapitalexport. Dies deshalb, weil die reinvestierten Erträge einiger Direktinvestitionen von Dienstleistungsunternehmen in Zypern und Gibraltar erhebliche Schwankungen aufwiesen.

\section{$\square$ Asiatische Schwellen- und Entwicklungsländer}

Zusammen mit den mittelamerikanischen Finanzzentren sind die asiatischen Schwellenländer die bedeutendsten Direktinvestitionsstandorte ausserhalb der Industrieländer. Der Export von Direktinvestitionskapital in diese Region betrug 1993 0,7 Mrd. Franken. Mit Ausnahme des Jahres 1995, als aus Hongkong Kapital abgezogen wurde, nahm dieser Finanzstrom stetig zu und erreichte 1998 5,7 Mrd. Franken. Ein Ergebnis, das dann allerdings im folgenden Jahr nicht mehr ganz erreicht wurde. Grosse Bedeutung hatten die reinvestierten Erträge, die 1998/99 gut die Hälfte des gesamten Kapitalexports ausmachten.

Der Bestand der Direktinvestitionen in den asiatischen Schwellenländern betrug Ende 1999 20,7 Mrd. Franken. Bis 1996 wies Hongkong den höchsten Kapitalbestand auf, danach wurde aber Singapur zum kapitalmässig wichtigsten 
Direktinvestitionsstandort. In Hongkong und Singapur zusammen waren Ende 1999 knapp 16 Mrd. Franken investiert, rund 70\% in Auslandsbeteiligungen von Finanz- und Holdinggesellschaften. Die Investitionen in den Philippinen, in Malaysia, Südkorea, Thailand und Taiwan hatten Ende 1999 einen Bestand von 4,7 Mrd. Franken, knapp zwei Drittel davon waren Direktinvestitionen der Industrie. Mit 70\% der 102'400 Arbeitsplätze der Region war der Anteil der erwähnten fünf Länder beim Personal deutlich höher als beim Kapitalbestand.

Der Kapitalexport in den Nahen Osten lag in der Periode 1993-99 im Durchschnitt bei knapp 0,1 Mrd. Franken pro Jahr. Zielländer des schweizerischen Direktinvestitionskapitals waren vor allem Israel und Saudi-Arabien. Im Jahre 1999 erreichte der Kapitalbestand in der Region 1,1 Mrd. Franken. Gut zwei Drittel davon hielten Investoren aus der Industrie.

Der Kapitalexport für Direktinvestitionen in die übrigen asiatischen Entwicklungsländer betrug im Jahre 1993 erst 0,1 Mrd. Franken, stieg dann aber bis 1996 auf 1 Mrd. Franken, ein mit den Investitionen in den asiatischen Schwellenländern vergleichbares Volumen. Dabei handelte es sich anfänglich vor allem um Investitionen in China, später gewannen dann Indien und Indonesien als Investitionsstandorte an Bedeutung. Während der Finanzfluss in die Schwellenländer nach 1996 weiter zunahm, verminderte sich der Kapitalexport in die Entwicklungsländer. Der Zustrom von Beteiligungskapital ging von 0,8 Mrd. im Jahre 1996 auf 0,3 Mrd. Franken im Jahre 1999 zurück. Wegen erheblicher Verluste in Unternehmen der Industrie in China resultierte 1999 insgesamt sogar ein Kapitalabbau in den asiatischen Entwicklungsländern.

Der Bestand der Direktinvestitionen in den asiatischen Entwicklungsländern (ohne Nahost) betrug 19993 Mrd. Franken. Rund 70\% davon waren Investitionen der Industrie. Knapp die Hälfte der Investitionen befanden sich in China. Auf Indien und Indonesien zusammen entfiel ein Kapitalbestand von 0,9 Mrd. Franken. Die übrigen Investitionen lagen vor allem in Pakistan, Vietnam, Sri Lanka, Bangladesch; seit 1997 bzw. 1999 auch in Myanmar und Kazachstan.

\section{$\square$ Mittel- und Südamerika}

Der Export von Direktinvestitionskapital in die mittel- und südamerikanischen Schwellenländer betrug 1993-97 durchschnittlich 0,2 Mrd., übertraf dann aber 1998/99 1 Mrd. Franken pro Jahr. Der Kapitalbestand erreichte im Jahre 1999 11 Mrd. Franken. Etwa 45\% des Kapitals waren in Brasilien, 35\% in Mexiko und je etwa 10\% in Argentinien und Chile investiert. Bis 1996 dominierten die Kapitalexporte der Industrie. In den Jahren 1997/98 zog die Industrie aber vorübergehend Kapital zurück und 1998/99 erfolgten grössere Investitionen des Dienstleistungssektors (einschliesslich Finanz- und Holdinggesellschaften). Der Anteil der Industrie am Investitionsbestand fiel deshalb von 75\% Ende 1996 auf noch knapp 60\% im Jahre 1999.

Der Hauptteil des in den mittel- und südamerikanischen Entwicklungsländern investierten Direktinvestitionskapital entfällt auf die Offshore-Finanzzentren. Ende 1999 betrug das Direktinvestitionskapital 26 Mrd. Franken, vor allem auf Bermuda, den Kaimaninseln sowie auf den Niederländischen Antillen. ${ }^{4}$ Die

4. Offshore-Finanzzentren gemäss der Geonomenklatur von Eurostat: Bahamas, Barbados, Bermuda, Britische Jungferninseln, Jamaica, Kaimaninseln, Montserrat, Niederländischen Antillen, Panama, St. Kitts und Nevis. 
Hauptinvestoren sind Dienstleistungsunternehmen, aber auch die Industrie sowie die Finanz- und Holdinggesellschaften halten erhebliche Beteiligungen in dieser Region. Die Kapitalströme mit dieser Region sind starken Schwankungen unterworfen. In der Periode 1993-99 reichte das Spektrum von einem Kapitalabzug von 0,9 Mrd. (1994) bis zu einem Kapitalexport von 4,6 Mrd. Franken (1999).

Der Kapitalexport in die mittel- und südamerikanischen Entwicklungsländer ohne die Offshore-Finanzzentren war 1993-96 durchschnittlich knapp 0,2 Mrd., 1997-99 dann gut 0,6 Mrd. Franken pro Jahr. Der Bestand der Direktinvestitionen erreichte Ende 1999 3,6 Mrd. Franken, die Beschäftigung 35’200 Personen. Etwa die Hälfte des Kapitalbestandes entfiel auf Investitionen in Kolumbien und Venezuela. Gemessen am Kapitalbestand waren die Auslandsbeteiligungen Uruguay und Ecuador von Bedeutung, gemessen am Personalbestand auch solche in Peru, Costa Rica und Guatemala. Wie in den Schwellenländern gewannen auch in den Entwicklungsländern die Investitionen des Dienstleistungssektors seit 1997 an Bedeutung, doch stammten auch Ende 1999 noch drei Viertel der Investitionen von Unternehmen aus der Industrie.

\section{Afrika}

Die Kapitalexporte nach Afrika betrugen 1993-96 durchschnittlich knapp 0,2 Mrd., danach gut 0,3 Mrd. Franken pro Jahr. Damit flossen im Zeitraum 1993-99 nur 4\% des für die Tranformations-, Schwellen- und Entwicklungsländer bestimmten Direktinvestitionskapitals nach Afrika. Der Bestand der Direktinvestitionen erreichte Ende 1999 3,9 Mrd. Franken. Davon waren 0,8 Mrd. Franken in Nordafrika investiert, hauptsächlich in Ägypten und Marokko. Von den in den übrigen afrikanischen Ländern angelegten 3,1 Mrd. entfielen 1,3 Mrd. Franken auf Südafrika. Von den Investitionen in Südafrika stammten gut die Hälfte der Investitionen von Investoren aus der Industrie, je knapp ein Viertel von Investoren aus dem Dienstleistungssektor bzw. von Finanz- und Holdinggesellschaften. In den südafrikanischen Direktinvestitionsunternehmen waren Ende 1999 gut 20'000 Personen beschäftigt. Weitere 21'000 Arbeitsplätze befanden sich in Nigeria, Botsuana, Namibia, Elfenbeinküste, Tansania, Kenia, Kamerun und Simbabwe. Der Kapitalbestand in diesen Ländern belief sich auf rund 1 Mrd. Franken. Liberia und Mauritius, zwei Länder, die auf Offshore-Finanzaktivitäten ausgerichtet sind, wiesen zusammen einen Kapitalbestand von 0,8 Mrd. Franken und weniger als 100 Beschäftigte aus.

\section{Schlussbetrachtung}

Die Vorstellung der Ergebnisse der Direktinvestitionsstatistik in diesem Abschnitt ist natürlich keinesfalls als abschliessend zu betrachten. Verschiedene Fragen hinsichtlich der schweizerischen Beteiligungen in den Transformations-, Schwellen- und Entwicklungsländern dürften unbeantwortet geblieben sein. Hoffentlich wurden aber einige Aspekte aufgezeigt, welche zusammen mit den methodischen Ausführungen des zweiten und dritten Abschnitts zur Klärung spezifischer Fragestellungen beitragen. 
Tabelle 1: Schweizerische Direktinvestitionen im Ausland, Ländergliederung

\begin{tabular}{|c|c|c|c|c|c|c|c|c|c|}
\hline \multirow[t]{2}{*}{ Region / Land } & \multicolumn{6}{|c|}{ Kapitalexport (Mio. Fr.) } & \multicolumn{2}{|r|}{$\begin{array}{r}\text { Kapitalbestand } \\
\text { (Mio. Fr.) }\end{array}$} & \multirow{2}{*}{$\begin{array}{r}\text { Personalbestand } \\
\text { (gerundet) } \\
1999\end{array}$} \\
\hline & 1993 & 1994 & 1995 & 1996 & 1997 & 1998 & 1999 & 1999 & \\
\hline EU und EFTA & 3290 & 8047 & 6251 & 12576 & 12776 & 10061 & 25234 & 148436 & 774500 \\
\hline Aussereuropäische Industrieländer & 6079 & 5837 & 6583 & 4421 & 8306 & 5165 & 15266 & 81063 & 336200 \\
\hline Mittel- und Osteuropa & 162 & 334 & 901 & 361 & 215 & 1175 & 1141 & 6139 & 71900 \\
\hline davon: Kroatien & 6 & 14 & 4 & 5 & 4 & 70 & -44 & 158 & 2200 \\
\hline Polen & 38 & 159 & 236 & 113 & 173 & 208 & 478 & 1665 & 20000 \\
\hline Russische Föderation & -8 & 56 & 37 & 100 & 46 & 335 & 599 & 1198 & 9700 \\
\hline Slowakei & 0 & 0 & 3 & -2 & 13 & 21 & 40 & 153 & 3600 \\
\hline Tschechische Republik & 54 & 34 & 573 & 61 & -19 & 356 & -72 & 1630 & 14900 \\
\hline Ungarn & 34 & 52 & 31 & 62 & -35 & -76 & 80 & 851 & 9700 \\
\hline Übriges Europa & 32 & 24 & 121 & 49 & 314 & -449 & 734 & 2721 & 10800 \\
\hline davon: Türkei & 41 & -8 & 96 & 0 & 51 & 296 & -95 & 1013 & 10100 \\
\hline Asiatische Schwellenländer & 710 & 760 & -242 & 1146 & 2383 & 5689 & 4662 & 20691 & 102400 \\
\hline davon: Hongkong & 300 & 420 & -547 & 21 & 236 & 447 & 648 & 2187 & 14200 \\
\hline Süd-Korea & 12 & 29 & 19 & 66 & -57 & 283 & 179 & 1040 & 4700 \\
\hline Malaysia & 104 & 8 & 17 & 233 & 82 & 102 & 229 & 937 & 12800 \\
\hline Philippinen & 74 & 14 & -8 & 39 & 50 & 1169 & 57 & 1433 & 13100 \\
\hline Singapur & 127 & 110 & 175 & 542 & 1879 & 3173 & 3543 & 13738 & 19400 \\
\hline Taiwan & 70 & 93 & 61 & 22 & 45 & 121 & 89 & 644 & 9900 \\
\hline Thailand & 23 & 86 & 41 & 224 & 148 & 395 & -82 & 712 & 28200 \\
\hline
\end{tabular}




\begin{tabular}{|c|c|c|c|c|c|c|c|c|c|}
\hline Naher Osten & 13 & 49 & 31 & 258 & 30 & 36 & 100 & 1112 & 11800 \\
\hline davon: Israel & 30 & 12 & 0 & 261 & -26 & 51 & 26 & 479 & 5300 \\
\hline Libanon & -27 & 3 & 9 & 8 & 2 & -2 & -13 & 120 & 900 \\
\hline Saudi-Arabien & 2 & 33 & 4 & 3 & 43 & -2 & 60 & 323 & 2900 \\
\hline Vereinigte Arabische Emirate & 7 & 10 & 3 & 3 & 12 & 11 & 19 & 143 & 1200 \\
\hline
\end{tabular}

\begin{tabular}{|c|c|c|c|c|c|c|c|c|c|}
\hline \multicolumn{10}{|l|}{ Übrige asiatische } \\
\hline Entwicklungsländer & 127 & 198 & 428 & 976 & 599 & 404 & -39 & 2974 & 82400 \\
\hline davon: China & 32 & 168 & 342 & 378 & 255 & 123 & -116 & 1387 & 37100 \\
\hline Indien & 56 & 31 & 13 & 370 & 160 & 29 & -53 & 524 & 19400 \\
\hline Indonesien & 21 & 15 & 46 & 177 & 134 & 90 & 58 & 377 & 10000 \\
\hline Pakistan & 3 & -17 & 23 & 22 & 34 & -17 & 7 & 192 & 4300 \\
\hline Vietnam & 0 & -1 & 2 & 25 & 21 & -2 & -18 & 131 & 5100 \\
\hline
\end{tabular}

\begin{tabular}{|c|c|c|c|c|c|c|c|c|c|}
\hline \multicolumn{10}{|c|}{ Mittel- und südamerikanische } \\
\hline Schwellenländer & 582 & 103 & 186 & 260 & -207 & 1243 & 1310 & 11034 & 122900 \\
\hline davon: Argentinien & 46 & 47 & 28 & 65 & -10 & 321 & -99 & 1317 & 13000 \\
\hline Brasilien & 308 & -54 & 127 & -10 & -338 & 446 & 853 & 5043 & 72000 \\
\hline Chile & 106 & 27 & 35 & 83 & 29 & -178 & 7 & 762 & 10100 \\
\hline Mexiko & 122 & 84 & -3 & 121 & 111 & 654 & 548 & 3911 & 27800 \\
\hline
\end{tabular}

\begin{tabular}{|c|c|c|c|c|c|c|c|c|c|}
\hline \multicolumn{10}{|c|}{ Mittel- und südamerikanische } \\
\hline Entwicklungsländer ${ }^{1}$ & 15 & 173 & 115 & 315 & 698 & 654 & 578 & 3642 & 35200 \\
\hline davon: Costa Rica & -3 & -16 & 45 & 10 & -1 & -26 & 0 & 180 & 2900 \\
\hline Ecuador & 15 & 4 & 11 & 80 & 27 & 10 & 20 & 376 & 3400 \\
\hline Guatemala & 19 & -5 & 4 & -176 & 60 & -4 & 22 & 145 & 1500 \\
\hline Kolumbien & 19 & 90 & 7 & 82 & 34 & 387 & 116 & 1165 & 8500 \\
\hline Peru & 2 & 9 & 19 & -9 & 158 & -25 & 47 & 262 & 3900 \\
\hline Uruguay & 40 & 56 & 92 & 172 & 217 & 284 & 287 & 436 & 800 \\
\hline Venezuela & 46 & -1 & -5 & 121 & 97 & 61 & 11 & 696 & 8500 \\
\hline
\end{tabular}


Tabelle 1: Schweizerische Direktinvestitionen im Ausland, Ländergliederung

\begin{tabular}{|c|c|c|c|c|c|c|c|c|c|}
\hline \multirow{2}{*}{ Region / Land } & \multicolumn{6}{|c|}{ Kapitalexport (Mio. Fr.) } & \multicolumn{2}{|r|}{$\begin{array}{r}\text { Kapitalbestand } \\
\text { (Mio. Fr.) }\end{array}$} & \multirow{2}{*}{$\begin{array}{r}\text { Personalbestand } \\
\text { (gerundet) } \\
1999\end{array}$} \\
\hline & 1993 & 1994 & 1995 & 1996 & 1997 & 1998 & 1999 & 1999 & \\
\hline \multicolumn{10}{|l|}{ Mittelamerikanische } \\
\hline Offshore-Finanzzentren & 1876 & -864 & -113 & -583 & 236 & 2991 & 4589 & 26057 & 6500 \\
\hline Nordafrika & 19 & 41 & 51 & 41 & 128 & 47 & 95 & 823 & 13700 \\
\hline davon: Ägypten & 12 & 33 & 34 & 18 & 92 & 57 & 93 & 472 & 8400 \\
\hline Marokko & 6 & -1 & 8 & 19 & 32 & -12 & 3 & 317 & 3500 \\
\hline Übriges Afrika & 43 & 60 & 125 & 142 & 256 & 194 & 336 & 3108 & 45400 \\
\hline davon: Elfenbeinküste & -10 & -6 & 6 & 17 & 16 & 51 & -28 & 110 & 2200 \\
\hline Nigeria & 6 & 14 & -2 & 1 & -9 & 5 & -6 & 36 & 5500 \\
\hline Südafrika & 37 & 48 & 151 & 93 & 154 & 138 & 140 & 1315 & 20600 \\
\hline Alle Länder & 12949 & 14761 & 14438 & 19964 & 25734 & 27209 & 54005 & 307798 & 1613600 \\
\hline
\end{tabular}

1. Ohne mittelamerikanische Offshore-Finanzzentren. 


\section{Tabelle 2: Schweizerische Direktinvestitionen im Ausland, Gliederung nach Sektoren}

\begin{tabular}{|c|c|c|c|c|c|c|c|c|c|}
\hline \multirow{2}{*}{ Region / Sektor } & \multicolumn{6}{|c|}{ Kapitalexport (Mio. Fr.) } & \multicolumn{2}{|r|}{$\begin{array}{r}\text { Kapitalbestand } \\
\text { (Mio. Fr.) }\end{array}$} & \multirow{2}{*}{$\begin{array}{r}\text { Personalbestand } \\
\text { (gerundet) } \\
1999 \\
\end{array}$} \\
\hline & 1993 & 1994 & 1995 & 1996 & 1997 & 1998 & 1999 & 1999 & \\
\hline \multicolumn{10}{|l|}{ EU und EFTA } \\
\hline Alle Unternehmen & 3290 & 8047 & 6251 & 12576 & 12776 & 10061 & 25234 & 148436 & 774500 \\
\hline Industrie & 2606 & 3438 & 3448 & 4967 & 6036 & 3322 & 3897 & 52229 & 433000 \\
\hline Dienstleistungen' & 1524 & 3927 & 2442 & 5549 & 2563 & 4666 & 14600 & 52828 & 175100 \\
\hline Finanz- und Holdinggesellschaften & -840 & 682 & 361 & 2060 & 4178 & 2074 & 6737 & 43379 & 166300 \\
\hline \multicolumn{10}{|l|}{ Aussereuopäische Industrieländer } \\
\hline Alle Unternehmen & 6079 & 5837 & 6583 & 4421 & 8306 & 5165 & 15266 & 81063 & 336200 \\
\hline Industrie & 1560 & 4566 & 5778 & 2091 & 7381 & 686 & 4401 & 26182 & 187800 \\
\hline Dienstleistungen & 1974 & 231 & 869 & 2185 & 260 & 3716 & 8765 & 46280 & 87600 \\
\hline Finanz- u. Holdinggesellschaften & 2545 & 1041 & -63 & 145 & 665 & 763 & 2099 & 8601 & 60800 \\
\hline
\end{tabular}

\section{Mittel- und Osteuropa}

$\begin{array}{llllllll}\text { Alle Unternehmen } & 162 & 334 & 901 & 361 & 215 & 1175 & 1141\end{array}$

Industrie

$\begin{array}{rrrrrrrrr}162 & 334 & 901 & 361 & 215 & 1175 & 1141 & 6139 & 71900 \\ 95 & 192 & 231 & 197 & 151 & 422 & 540 & 2439 & 45400\end{array}$

Dienstleistungen'

$56 \quad 85$

Finanz- und Holdinggesellschaften

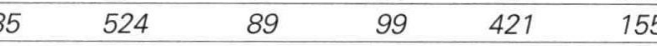

446

\section{Übriges Europa}

Alle Unternehmen

Industrie

$32-24$

Dienstleistungen

1136

Finanz- und Holdinggesellschaften

6

36
9

$\begin{array}{rr}121 & 49 \\ 55 & -26\end{array}$

$49 \quad 314$

$\begin{array}{llll}314 & -449 & 734 & 2721\end{array}$ 480

$\begin{array}{rrrrrr}26 & 38 & 117 & 6 & 480 & 4700 \\ 70 & 289 & -683 & 530 & 1743 & 4300\end{array}$

497

$5-13$

$118 \quad 198$


Tabelle 2: Schweizerische Direktinvestitionen im Ausland, Gliederung nach Sektoren

\begin{tabular}{|c|c|c|c|c|c|c|c|c|c|}
\hline \multirow{2}{*}{ Region / Sektor } & \multicolumn{6}{|c|}{ Kapitalexport (Mio. Fr.) } & \multicolumn{2}{|r|}{$\begin{array}{r}\text { Kapitalbestand } \\
\text { (Mio. Fr.) }\end{array}$} & \multirow{2}{*}{$\begin{array}{r}\text { Personalbestand } \\
\text { (gerundet) } \\
1999 \\
\end{array}$} \\
\hline & 1993 & 1994 & 1995 & 1996 & 1997 & 1998 & 1999 & 1999 & \\
\hline \multicolumn{10}{|l|}{ Asiatische Schwellenländer } \\
\hline Alle Unternehmen & 710 & 760 & -242 & 1146 & 2383 & 5689 & 4662 & 20691 & 102400 \\
\hline Industrie & 158 & 271 & 41 & 218 & 435 & 3365 & 166 & 5290 & 56100 \\
\hline Dienstleistungen' & 143 & -124 & 69 & 541 & 171 & 579 & 1868 & 3144 & 27800 \\
\hline Finanz- und Holdinggesellschaften & 409 & 613 & -351 & 388 & 1777 & 1745 & 2628 & 12257 & 18500 \\
\hline
\end{tabular}

\section{Naher Osten}

\begin{tabular}{lrrrrrrrr} 
Alle Unternehmen & 13 & 49 & 31 & 258 & 30 & 36 & 100 & 11800 \\
\hline Industrie & 32 & 19 & 19 & 268 & 1 & 82 & 69 & 779 \\
\hline Dienstleistungen' & -19 & 30 & 11 & -31 & 8 & -41 & 29 & 9500 \\
\hline Finanz- und Holdinggesellschaften $^{\prime} 1$ & 0 & 1 & 21 & 22 & -5 & 2 & 2100 \\
\hline
\end{tabular}

\begin{tabular}{lrrrrrrrrr}
\hline $\begin{array}{l}\text { Übrige asiatische Entwicklungsländer } \\
\text { Alle Unternehmen }\end{array}$ & 127 & 198 & 428 & 976 & 599 & 404 & -39 & 2974 & 82400 \\
\hline Industrie & 104 & 174 & 322 & 488 & 463 & 88 & -223 & 2031 & 66500 \\
\hline Dienstleistungen' & 22 & 21 & 92 & 421 & 82 & 193 & 118 & 422 & 8800 \\
\hline Finanz- und Holdinggesellschaften & 1 & 2 & 14 & 68 & 53 & 124 & 66 & 521 & 7100 \\
\hline
\end{tabular}

Mittel- und südamerikanische Schwellenländer

\begin{tabular}{|c|c|c|c|c|c|c|c|c|c|}
\hline Alle Unternehmen & 582 & 103 & 186 & 260 & -207 & 1243 & 1310 & 11034 & 122900 \\
\hline Industrie & 570 & 418 & 85 & 241 & -123 & -768 & 993 & 6503 & 75500 \\
\hline Dienstleistungen' & 15 & 12 & 70 & 85 & 79 & 1034 & 179 & 1735 & 13100 \\
\hline Finanz- und Holdinggesellschaften & -3 & -327 & 31 & -66 & -163 & 977 & 138 & 2796 & 34300 \\
\hline
\end{tabular}


Mittel- und südamerikanische Entwicklungsländer ${ }^{2}$

\begin{tabular}{|c|c|c|c|c|c|c|c|c|c|}
\hline Alle Unternehmen & 15 & 173 & 115 & 315 & 698 & 654 & 578 & 3642 & 35200 \\
\hline Industrie & 117 & 89 & 69 & 224 & 521 & 430 & 330 & 2737 & 20900 \\
\hline Dienstleistungen' & 26 & 46 & 0 & 58 & 144 & 4 & 185 & 603 & 5600 \\
\hline Finanz- und Holdinggesellschaften & -128 & 38 & 46 & 33 & 33 & 219 & 63 & 302 & 8700 \\
\hline
\end{tabular}

\section{Mittelamerikanische Offshore-Finanzzentren}

\begin{tabular}{|c|c|c|c|c|c|c|c|c|c|}
\hline Alle Unternehmen & 1876 & -864 & -113 & -583 & 236 & 2991 & 4589 & 26057 & 6500 \\
\hline Industrie & 1561 & 908 & -1310 & -220 & 718 & 1671 & 594 & 4482 & 3400 \\
\hline Dienstleistungen' & 635 & -18 & 1460 & 308 & 873 & 1106 & 3281 & 15641 & 1400 \\
\hline Finanz- und Holdinggesellschaften & -320 & -1754 & -263 & -672 & -1355 & 214 & 713 & 5934 & 1700 \\
\hline
\end{tabular}

\section{Nordafrika}

\begin{tabular}{|c|c|c|c|c|c|c|c|c|c|}
\hline Alle Unternehmen & 19 & 41 & 51 & 41 & 128 & 47 & 95 & 823 & 13700 \\
\hline Industrie & 13 & 24 & 34 & 41 & 80 & 44 & 55 & 480 & 10800 \\
\hline Dienstleistungen ${ }^{\prime}$ & 5 & 17 & 16 & 2 & 46 & 30 & 23 & 321 & 2600 \\
\hline Finanz- und Holdinggesellschaften & 1 & 0 & 1 & -2 & 2 & -28 & 17 & 22 & 200 \\
\hline
\end{tabular}

\section{Übriges Afrika}

\begin{tabular}{|c|c|c|c|c|c|c|c|c|c|}
\hline Alle Unternehmen & 43 & 60 & 125 & 142 & 256 & 194 & 336 & 3108 & 45400 \\
\hline Industrie & -17 & -35 & 69 & 63 & 103 & 183 & -160 & 925 & 20900 \\
\hline Dienstleistungen' & 48 & 76 & 31 & 48 & 122 & -15 & 359 & 787 & 7800 \\
\hline Finanz- und Holdinggesellschaften & 11 & 19 & 25 & 31 & 32 & 26 & 137 & 1396 & 16700 \\
\hline
\end{tabular}

\section{Alle Länder}

\begin{tabular}{lrrrrrrrrr} 
Alle Unternehmen & 12949 & 14761 & 14438 & 19964 & 25734 & 27209 & 54005 & 307798 & 1613600 \\
\hline Industrie & 6814 & 10043 & 8838 & 8551 & 15804 & 9640 & 10667 & 104557 & 934500 \\
\hline Dienstleistungen' & 4440 & 4338 & 5638 & 9326 & 4735 & 11010 & 30093 & 125949 \\
\hline Finanz- $u$. Holdinggesellschaften & 1695 & 380 & -38 & 2087 & 5195 & 6559 & 13245 & 346200 \\
\hline
\end{tabular}

1. Ohne Finanz- und Holdinggesellschaften.

2. Ohne mittelamerikanische Offshore-Finanzzentren. 
Tabelle 3: Schweizerische Direktinvestitionen im Ausland, Gliederung nach Kapitalart

\begin{tabular}{|c|c|c|c|c|c|c|c|c|}
\hline \multirow{2}{*}{ Region / Kapitalart } & \multicolumn{6}{|c|}{ Kapitalexport (Mio. Fr.) } & & \multirow{2}{*}{$\begin{array}{r}\text { Kapitalbestand' } \\
\text { (Mio. Fr.) } \\
1999 \\
\end{array}$} \\
\hline & 1993 & 1994 & 1995 & 1996 & 1997 & 1998 & 1999 & \\
\hline \multicolumn{9}{|l|}{ EU und EFTA } \\
\hline Total & 3290 & 8047 & 6251 & 12576 & 12776 & 10061 & 25234 & 148436 \\
\hline Beteiligungskapital & 2634 & 7662 & 3846 & 8739 & 7688 & 4331 & 16623 & 131318 \\
\hline Reinvestierte Erträge & 1311 & 787 & 1261 & 3813 & 5177 & 4201 & 5139 & \\
\hline Kredite & -655 & -403 & 1143 & 24 & -89 & 1529 & 3473 & 17118 \\
\hline
\end{tabular}

\section{Aussereuropäische Industrieländer}

\begin{tabular}{lrrrrrrrr}
\hline Total & 6079 & 5837 & 6583 & 4421 & 8306 & 5165 & 15266 & 81063 \\
\hline Beteiligungskapital & 2617 & 5300 & 3670 & 3179 & 2500 & 1553 & 6178 & 62617 \\
\hline Reinvestierte Erträge & 1363 & 1178 & 1641 & 1264 & 1646 & 3099 & 5556 \\
\hline Kredite & 2099 & -640 & 1272 & -22 & 4160 & 512 & 3532 \\
\hline
\end{tabular}

\section{Mittel- und Osteuropa}

\begin{tabular}{lrrrrrrrr}
\hline Total & 162 & 334 & 901 & 361 & 215 & 1175 & 1141 & 6139 \\
\hline Beteiligungskapital & 112 & 251 & 925 & 179 & 226 & 766 & 540 & 4942 \\
\hline Reinvestierte Erträge & 8 & 13 & -53 & 89 & -32 & -244 & 358 \\
\hline Kredite & 43 & 70 & 29 & 93 & 21 & 653 & 243 & 1196 \\
\hline
\end{tabular}

\section{Übriges Europa}

\begin{tabular}{lrrrrrrrrr}
\hline Total & 32 & 24 & 121 & 49 & 314 & -449 & 734 & 2721 \\
\hline Beteiligungskapital & 26 & 34 & 72 & 45 & 193 & 385 & 288 & 2302 \\
\hline Reinvestierte Erträge & -5 & 2 & 28 & 51 & 108 & -956 & 375 \\
\hline Kredite & 12 & -12 & 21 & -47 & 13 & 122 & 71 & 419 \\
\hline
\end{tabular}


Asiatische Schwellenländer

\begin{tabular}{lrrrrrrrr}
\hline Total & 710 & 760 & -242 & 1146 & 2383 & 5689 & 4662 & 20691 \\
\hline Beteiligungskapital & 355 & -60 & 80 & 865 & 796 & 3861 & 1648 & 19181 \\
\hline Reinvestierte Erträge & 362 & 254 & 198 & 481 & 1355 & 1794 & 3613 \\
\hline Kredite & -7 & 566 & -519 & -200 & 232 & 33 & -599 & 1510 \\
\hline
\end{tabular}

\begin{tabular}{lrrrrrrrr}
\hline Naher Osten & 13 & 49 & 31 & 258 & 30 & 36 & 100 & \\
\hline Total & -31 & 27 & 19 & 246 & 45 & 59 & 34 \\
\hline Beteiligungskapital & 27 & 20 & 22 & -4 & 6 & -34 & 34 \\
\hline Reinvestierte Erträge & 17 & 2 & -10 & 16 & -20 & 11 & 32 \\
\hline Kredite & 93
\end{tabular}

\begin{tabular}{lrrrrrrr}
\hline Übrige asiatische Entwicklungsländer & & & & & & \\
\hline Total & 127 & 198 & 428 & 976 & 599 & 404 & -39 \\
\hline Beteiligungskapital & 83 & 71 & 412 & 801 & 589 & 406 & 251 \\
\hline Reinvestierte Erträge & 28 & 33 & -25 & 28 & -98 & -169 & -298 \\
\hline Kredite & 16 & 93 & 41 & 148 & 108 & 167 & 8 \\
\hline
\end{tabular}

Mittel- und südamerikanische Schwellenländer

\begin{tabular}{lrrrrrrrr}
\hline Mittel- und südamerikanische Schwellenländer & 582 & 103 & 186 & 260 & -207 & 1243 & 1310 & 11034 \\
\hline Total & 325 & -475 & 118 & -54 & -232 & 1465 & 791 & 9869 \\
\hline Beteiligungskapital & 230 & 547 & 92 & -36 & -12 & -437 & 316 \\
\hline Reinvestierte Erträge & -101 & 31 & -23 & 350 & 37 & 215 & 203 & 1166 \\
\hline Kredite & & & & \\
\hline
\end{tabular}

\section{Mittel- und südamerikanische Entwicklungsländer ${ }^{2}$}

\begin{tabular}{lrrrrrrrr}
\hline Motal $^{\prime}$ & 15 & 173 & 115 & 315 & 698 & 654 & 578 & 3642 \\
\hline Beteiligungskapital & 57 & 46 & 83 & -193 & 75 & 366 & 169 & 3246 \\
\hline Reinvestierte Erträge & 76 & 114 & 120 & 240 & 409 & 237 & 451 \\
\hline Kredite & 10 & 13 & -88 & 268 & 214 & 50 & -42 & 396 \\
\hline
\end{tabular}


Tabelle 3: Schweizerische Direktinvestitionen im Ausland, Gliederung nach Kapitalart

\section{Region / Kapitalart \\ Kapitalexport (Mio. Fr.)}

Kapitalbestand

(Mio. Fr.)

$\frac{1993}{\text { Mittel- und südamerikanische Entwicklungsländer }^{2}}$

\begin{tabular}{lrrrrrrrr}
\hline Mittel- und südamerikanische Entwicklungslander $^{2}$ & 15 & 173 & 115 & 315 & 698 & 654 & 578 & 3642 \\
\hline Total & 57 & 46 & 83 & -193 & 75 & 366 & 169 \\
\hline Beteiligungskapital & 76 & 114 & 120 & 240 & 409 & 237 & 451 \\
\hline Reinvestierte Erträge & 10 & 13 & -88 & 268 & 214 & 50 & -42 \\
\hline Kredite & & & 396 \\
\hline
\end{tabular}

\section{Mittelamerikanische Offshore-Finanzzentren}

\begin{tabular}{lrrrrrrrr}
\hline Mittelamerikanische Offshore-Finanzzentren & 1876 & -864 & -113 & -583 & 236 & 2991 & 4589 & 26057 \\
\hline Total & 831 & -1695 & 315 & -751 & 1531 & 3780 & 713 & 25202 \\
\hline Beteiligungskapital & 1576 & 476 & 384 & 452 & 1142 & -383 & 2631 \\
\hline Reinvestierte Erträge & -530 & 355 & -812 & -284 & -2436 & -405 & 1246 & 855 \\
\hline Kredite & -530 & &
\end{tabular}

\section{Nordafrika}

\begin{tabular}{|c|c|c|c|c|c|c|c|c|}
\hline Total & 19 & 41 & 51 & 41 & 128 & 47 & 95 & 823 \\
\hline Beteiligungskapital & 44 & 27 & 31 & 24 & 28 & -22 & 25 & 702 \\
\hline Reinvestierte Erträge & -23 & 11 & 15 & 21 & 75 & 52 & 63 & \\
\hline Kredite & -2 & 3 & 6 & -3 & 25 & 16 & 7 & 121 \\
\hline \multicolumn{9}{|l|}{ Übriges Afrika } \\
\hline Total & 43 & 60 & 125 & 142 & 256 & 194 & 336 & 3108 \\
\hline Beteiligungskapital & 57 & 55 & 68 & 26 & 76 & -3 & 389 & 2667 \\
\hline Reinvestierte Erträge & -22 & 23 & 29 & 66 & 114 & 42 & 237 & \\
\hline Kredite & 8 & -17 & 28 & 50 & 66 & 155 & -290 & 441 \\
\hline
\end{tabular}

\section{Alle Länder}

\begin{tabular}{lrrrrrrrr}
\hline Total & 12949 & 14761 & 14438 & 19964 & 25734 & 27209 & 54005 & 307798 \\
\hline Beteiligungskapital & 7109 & 11244 & 9638 & 13106 & 13515 & 16949 & 27648 & 265432 \\
\hline Reinvestierte Erträge & 4931 & 3457 & 3711 & 6465 & 9889 & 7203 & 18474 \\
\hline Kredite & 909 & 61 & 1089 & 392 & 2331 & 3058 & 7883 & 42367 \\
\hline
\end{tabular}

1. Beteiligungskapital inkl. reinvestierte Erträge.

2. Ohne mittelamerikanische Offshore-Finanzzentren. 


\subsection{DIE OECD-LEITSÄTZE FÜR MULTINATIONALE UNTERNEHMEN}

\section{BAstienNe JoERCHEL ANHORN*}

Am 27. Juni 2000 haben 29 Mitgliedsstaaten der OECD sowie Argentinien, Brasilien, Chile und die Slowakei die revidierten «OECD-Leitsätze für multinationale Unternehmen» (kurz: «Leitsätze») verabschiedet. Die «Leitsätze» sind rechtlich nicht bindende Empfehlungen, die von den Regierungen an die multinationalen Unternehmen gerichtet werden, welche in den Ländern (oder von den Ländern aus) operieren, die die Leitsätze angenommen haben. Es handelt sich dabei um den bislang einzigen relativ vollständigen Verhaltenskodex für multinationale Unternehmen, der auf multilateraler Ebene angenommen wurde und zu dessen Förderung sich die Regierungen verpflichtet haben. Er hat zum Ziel, die multinationalen Firmen dazu anzuhalten, in sozialer und ökologischer Hinsicht und unter Einhaltung der geltenden nationalen und internationalen Gesetze verantwortungsvoll zu handeln. Die «Leitsätze» umfassen eine grosse Vielfalt von Themen betreffend die Aktivitäten der multinationalen Unternehmen: Beschäftigung, Umwelt, Offenlegung von Informationen, Wettbewerb, Besteuerung, Wissenschaft und Technologie. Neu eingeführt wurde eine Bezugnahme auf die Menschenrechte sowie zwei weitere Themen: Korruptionsbekämpfung und Verbraucherschutz.

Die Überprüfung der «Leitsätze» widerspiegelt die grossen politischen und wirtschaftlichen Veränderungen der letzten beiden Jahrzehnte, die durch die Globalisierung und die Liberalisierung des Welthandels gekennzeichnet waren. Sie entspricht bis zu einem gewissen Grad den Besorgnissen der Länder des Südens, der Zivilgesellschaft und der Nichtregierungsorganisationen (NRO) bezüglich der Unausgewogenheiten zwischen den Rechten und Pflichten der multinationalen Unternehmen, die auf dem internationalen Markt immer mächtiger werden. Die Überprüfung stellt auch insofern eine Wende dar, als sie den Zutritt der nichtstaatlichen Entwicklungs-, Umwelt- und Verbraucherorganisationen zur Bühne der internationalen Wirtschaftsverhandlungen bestätigt. Der von der OECD durchgeführte Revisionsprozess ist in der Tat ein Muster an Transparenz und Demokratie, da die NRO aufgefordert wurden, aktiv an den verschiedenen Verhandlungsphasen mitzuwirken.

Nutzen und Wirksamkeit eines nicht rechtsverbindlichen Instruments werfen jedoch in einem Kontext, wo sich allein die Gesetze des Marktes, der wirtschaftlichen Rentabilität und des Wettbewerbs durchzusetzen scheinen, eine Reihe Fragen auf. Dieser Artikel hat zum Ziel, auf den Verlauf der Revision zurückzukommen, um anschliessend die Stärken und Schwächen der an den «Leitsätzen» vorgenommenen Änderungen hervorzuheben. Ferner soll die Position der Nichtregierungsorganisationen vorgestellt werden, die an den Verhandlungen teilgenommen haben, indem sie sich im Rahmen eines europäischen Netzes zusammenschlossen, dessen Aktion sich als besonders wirksam erwiesen hat.

\footnotetext{
* Bastienne Joerchel Anhorn: Mitarbeiterin der Arbeitsgemeinschaft Swissaid, Fastenopfer, Brot für alle, Helvetas, Caritas, Lausanne.
} 


\section{GESCHICHTLICHER VERLAUF}

Die «Leitsätze» sind integrierender Bestandteil der «OECD-Erklärung über internationale Investitionen und multinationale Unternehmen» von 1976. Diese Erklärung, die vor über zwanzig Jahren in einem im Vergleich zu heute sehr unterschiedlichen wirtschaftlichen und politischen Kontext verabschiedet wurde, zielte darauf ab, die Rolle der Investitionen in der Weltwirtschaft und den Impakt der multilateralen Unternehmen auf die Volkswirtschaften klarzustellen. Die 70er Jahre waren in der Tat vom Aufkommen der transnationalen Unternehmen und einer zunehmenden Internationalisierung der Produktion geprägt. Zu dieser Zeit war es jedoch üblich, dass die öffentlichen Hände noch häufig in die Wirtschaft eingriffen. Massnahmen zur Kontrolle der Einführung und der Tätigkeit ausländischer Unternehmen auf dem nationalen Markt waren weit verbreitet.

Mit der Erklärung von 1976 liessen die OECD-Mitglieder eine doppelte Bestrebung erkennen. Einerseits den Willen, die Befugnisse der Regierungen gegenüber den multinationalen Firmen zu stärken, das heisst die Einhaltung der nationalen Gesetzgebungen sowie die Unterwerfung der Unternehmen unter die staatlichen Behörden zu gewährleisten, da diese Unternehmen finanziell immer mächtiger wurden und sich aufgrund ihrer internationalen Struktur den staatlichen Kontrollen entziehen konnten. Andererseits wollten die Regierungen, die sich der Anreizrolle bewusst waren, welche die ausländischen Direktinvestitionen spielen konnten, ein für diese Investitionen günstiges internationales Klima schaffen, das von den Grundsätzen der Chancengleichheit und der Nichtdiskriminierung geleitet wurde 5 .

Die politischen und wirtschaftlichen Umwälzungen der 80er und 90er Jahre haben die Situation seither stark verändert. Die Liberalisierungen und Deregulierungen haben zum Abbau der nationalen Schranken und zur Beseitigung der Hindernisse und Kontrollen geführt, welche den Zustrom ausländischer Direktinvestitionen und die Aktivitäten der multinationalen Unternehmen beschränkten. Der Handel mit Gütern und Dienstleistungen hat sich in diesen beiden Jahrzehnten mehr als verdreifacht. Gemäss der UNCTAD werden die ausländischen Direktinvestitionen im Jahr 2000 einen neuen Rekordwert von 1000 Milliarden Dollar erreichen ${ }^{6}$. Sie betrugen 1999 bereits 865 Milliarden Dollar, gegenüber 349 Milliarden Dollar 1997 und 53 Milliarden Dollar 1982. Diese Investitionen haben ihren Ursprung zu 80\% in den Zusammenlegungen und Übernahmen der transnationalen Grosskonzerne, von denen neun von zehn ihren Sitz in einem Industrieland in Europa oder Nordamerika haben.

In diesem neuen Kontext fanden die Verhandlungen der Uruguay-Runde statt, die 1995 zur Gründung der Welthandelsorganisation (WTO) führten. Das Ziel dieser Organisation, die heute 138 Mitgliedsländer umfasst, ist die allmähliche Liberalisierung des Welthandels und seine Regulierung. Dieses Ziel beruht auf der Überzeugung, die heutzutage noch von der überwiegenden Mehrheit der politischen und wirtschaftlichen Elite der Industrieländer geteilt wird, nämlich

5. «Les "Principes directeurs" de l'OCDE dans un monde en voie de mondialisation", Arghyrios A. Fatouros, überarbeitete Version eines Dokuments, das vom Verfasser an der Konferenz von Budapest über die «OECD-Leitsätze» im November 1998 unterbreitet wurde und von der Direktion der OECD für Finanz-, Steuer- und Unternehmensfragen veröffentlicht wurde.

6. Rapport mondial sur l'investissement 2000, CNUCED, 4. Oktober 2000. 
dass nur ein von jedem Hindernis völlig freier Weltmarkt zum Wachstum und zur wirtschaftlichen und sozialen Entwicklung des Planeten beitragen kann. Die WTO stellte gegenüber dem GATT (General Agreement on Tariffs and Trade) einen Schritt nach vorn dar. Zunächst hat sich ihr Anwendungsbereich beträchtlich erweitert, da dieser nicht nur Waren, sondern auch Dienstleistungen, geistiges Eigentum, Textilien und die Landwirtschaft umfasst. Sodann haben sich die Regeln - insbesondere mit dem Streitschlichtungssystem und der Möglichkeit der Anwendung von Sanktionen - verstärkt.

Die Industrieländer haben erfolglos versucht, die Investitionen in die Abkommen der WTO einzuschliessen. Angesichts der Weigerung der Mehrheit der Entwicklungsländer haben sie sich dann mit der OECD beschränkt, wo sie ab 1995 neue Verhandlungen für den Abschluss eines Multilateralen Abkommens über Investitionen (MAI) einleiteten. Die Idee war, die Verhandlung «unter Gleichgesinnten" rascher voranzubringen. Das Abkommen hätte in der Folge den anderen Ländern offenstehen sollen. Jedoch hat sich diese Verhandlung im Schutze der Kritik, weit davon entfernt, effizient zu sein, beim endgültigen Abschluss als verhängnisvolles Hindernis erwiesen. Die nichtstaatlichen Entwicklungs-, Umwelt- und Verbraucherschutzorganisationen sowie die Gewerkschaften haben nämlich den einseitigen Charakter des MAI scharf kritisiert, das sich darauf beschränkte, den multinationalen Firmen Rechte zu garantieren indem es ihnen in Bezug auf die Investitionen einen echten Blankoscheck ausstellte -, ohne ihnen jedoch vor allem ökologische und soziale Verpflichtungen aufzuerlegen.

Die «Leitsätze», welche die OECD-Staaten dem Abkommen als Anhang beifügen wollten, erwiesen sich dann als weitgehend unzureichend, um die den multinationalen Unternehmen angebotenen neuen Privilegien auszugleichen. Insbesondere waren die Kapitel über Sozial- und Umweltfragen weit davon entfernt, den Befürchtungen der Zivilgesellschaft Rechnung zu tragen. Die Investoren waren namentlich nicht verpflichtet, die internationalen Umwelt- und Sozialnormen einzuhalten, wie die Normen der Internationalen Arbeitsorganisation (IAO) über Gewerkschaftsrechte oder Kinderarbeit oder auch die in den verschiedenen multilateralen Umweltabkommen angeführten Normen. Wichtige Fragen wie nachhaltige Entwicklung oder Korruption wurden nicht einmal erwähnt. Und schliesslich rief der rechtlich nicht zwingende Charakter der «Leitsätze» heftige Kritik seitens der Nichtregierungsorganisationen hervor.

Der Druck der Zivilgesellschaft, eine scharfe Entschliessung des Europäischen Parlaments sowie der Sinneswandel Frankreichs in letzter Minute haben das Multilaterale Abkommen über Investitionen im Dezember 1998 zum Scheitern verurteilt. Angesichts dieses Fehlschlags haben die OECD-Staaten kurzfristig beschlossen, die Überprüfung der «Leitsätze», die einige Monate zuvor begonnen hatte, aktiv fortzusetzen.

\section{DIE ÜBERPRÜFUNG DER «LEITSÄTZE»}

Die «Leitsätze» sind periodischen Anpassungen unterzogen worden. Insbesondere fanden in den Jahren 1979, 1984 und 1991 Überprüfungen statt ; zum Beispiel wurde 1991 ein Kapitel über Umweltschutz hinzugefügt. Mit den Verhandlungen über das MAI traten die «Leitsätze» plötzlich ins Rampenlicht und 
riefen in der Öffentlichkeit ein Interesse hervor, das sie bis dahin nie erhalten hatten. Aus diesem Grunde nahm die Überarbeitung der «Leitsätze» eine für die Mehrheit der OECD-Mitglieder relativ unerwartete Dimension an, wobei letztere sich wahrscheinlich mit einer minimalistischeren Anpassung zufrieden gegeben hätten. Die Schweiz vertritt beispielsweise in einer Stellungnahme vom September 1998 die Ansicht, dass «grundlegende Änderungen nicht geboten sind ${ }^{7}$. Sie beschränkt sich wie Grossbritannien darauf, eine Anpassung der Kapitel über Umwelt und Beschäftigung «an die Entwicklungen der letzten Jahre» vorzuschlagen. Nur Frankreich vertritt eine ambitiösere Position, indem es den bei der OECD für die Verwaltung der «Leitsätze» verantwortlichen Ausschuss für internationale Investitionen und multinationale Unternehmen (CIME) im Juni 1998 auffordert, «über die Möglichkeit nachzudenken, gewisse Bestimmungen der "Leitsätze" rechtlich bindend zu machen ${ }^{8}$. Diese Entwicklung erschien Frankreich logisch, um für die im Entwurf des MAI vorgesehenen obligatorischen Bestimmungen über die Liberalisierung der Investitionen ein Gegengewicht zu bilden.

Somit werden sich die OECD-Mitglieder schliesslich erst nach dem Scheitern des MAI der augenscheinlichen Tatsache bewusst, dass eine gründliche Überarbeitung der «Leitsätze» unbedingt erforderlich ist, um sie dem neuen Kontext der Globalisierung anzupassen und dadurch gegenüber der Zivilgesellschaft und den NRO ihren guten Willen unter Beweis zu stellen. Demnach erfolgt 1999 eine allgemeine Reflexion über die Notwendigkeit, die Kapitel über Beschäftigung und Umwelt auszubauen. Neue Themen wie Korruption und Verbraucherschutz setzen sich nach und nach durch.

Zudem zeigen die OECD und ihre Mitglieder ein klares Bestreben, den Besorgnissen der Zivilgesellschaft entgegenzukommen, indem sie eine maximale Transparenz des Überprüfungsprozesses gewährleisten. Bereits im Frühjahr 1999 werden die NRO sogar aktiv an den verschiedenen Phasen der Revision beteiligt. Hierzu stellen sie eine informelle Koordinationsplattform auf europäischer Ebene auf und entsenden Vertreter, um an mehreren von der OECD abgehaltenen Treffen für ihren Standpunkt einzutreten. Die beiden offiziellen Beratungsgremien der OECD, der Beratende Ausschuss der Wirtschaft (BIAC) und der Gewerkschaftliche Beratungsausschuss (TUAC), nehmen ebenfalls an diesen Konsultationen teil. Ferner werden die Revisionsentwürfe regelmässig auf der Internet-Seite der OECD publiziert mit der Aufforderung an die Öffentlichkeit, Kommentare dazu abzugeben

In der Schweiz nimmt das mit der Angelegenheit beauftragte Staatssekretariat für Wirtschaft (seco) die Sitzungen der Liaisongruppe «Investitionen» zum Anlass, um die Wirtschafts- und Sozialkreise zu informieren und zu konsultieren. Die Liaisongruppe vereinigt unter anderen die Vertreter des Schweizerischen Handels- und Industrie-Vereins, der Vereinigung Schweizerischer Industrie-Holdinggesellschaften (Vertreter der Schweizer multinationalen Firmen), des Schweizerischen Bankvereins, des Schweizerischen Gewerkschaftsbundes, des Christlichnationalen Gewerkschaftsbundes der Schweiz sowie anderer

7. «Réexamen des "Principes directeurs" à l'intention des Entreprises Multinationales», Stellungnahme der Schweizer Delegation bei der OECD, September 1998, Seite 2.

8. «Examen des "Principes directeurs" de l'OCDE à l'intention des entreprises multinationales», Präsentation des einleitenden Standpunkts Frankreichs auf der Sitzung des CIME vom Juni 1998. 
Departemente der Bundesverwaltung. Die Arbeitsgemeinschaft Swissaid, Fastenopfer, Brot für alle, Helvetas, Caritas ist die einzige Entwicklungsorganisation, die seit 1996 zu diesen Treffen eingeladen wurde. Ebenfalls im Rahmen dieser Gruppe organisiert das seco Anfang des Jahres 2000 eine formelle Konsultation über den Vorentwurf der «Leitsätze», auf die die Arbeitsgemeinschaft mit einer ausführlichen Stellungnahme antwortet, welche sich an die Position der auf europäischer Ebene tätigen NRO anlehnt.

Dieses offene und flexible Revisionsverfahren führte zu sehr lebhaften Verhandlungen zwischen den verschiedenen an der Revision beteiligten Akteuren. Die im Juni 2000 angenommene endgültige Fassung widerspiegelt nicht nur die Interessenkonflikte zwischen dem Privatsektor und den NRO, sondern vor allem auch die Verschiedenheiten in Bezug auf die wirtschaftliche und politische Macht. Auf der einen Seite wurden die zahlreichen Merkmale der «Leitsätze» beibehalten, insbesondere ihr rechtlich nicht zwingender Charakter, der institutionelle Aufbau sowie die Umsetzungsverfahren, die praktisch unverändert bleiben. Auf der anderen Seite wurden bedeutende Fortschritte erzielt mit der Einführung von Bestimmungen über die Grundprinzipien des Menschen bei der Arbeit, wie sie von der IAO anerkannt werden: Gewerkschaftsfreiheit und Vertretungsrecht, Verbot der Zwangsarbeit, Abschaffung der Kinderarbeit, Nichtdiskriminierung. Die neuen Kapitel über Korruption und Verbraucherinteressen sowie die Anerkennung des Vorsorgeprinzips im Bereich der Umwelt und der öffentlichen Gesundheit tragen ebenfalls zur substantiellen Verbesserung der «Leitsätze» bei.

\section{DIE WICHTIGSTEN ÄNDERUNGEN}

Die Änderungen in der Einführung und im ersten Kapitel - «Begriffe und Grundsätze»- beinhalten hauptsächlich eine Beschreibung des neuen internationalen Kontexts, in dem sich die multinationalen Unternehmen heutzutage entwickeln. Der Text anerkennt ausdrücklich, dass die multinationalen Firmen auch eine Verantwortung zur Förderung der nachhaltigen Entwicklung haben. Der wesentliche Fortschritt liegt aber in der geographischen Ausdehnung des Anwendungsbereichs der «Leitsätze» auf alle Länder der Erde, in denen die multinationalen Unternehmen ihre Aktivitäten ausüben. Diese Forderung war von den NRO und den Gewerkschaften schon seit langem erhoben worden. In der Tat richten sich die Leitsätze an multinationale Unternehmen, die ihre Tätigkeit zwangsläufig oft über die Grenzen der OECD-Länder hinaus ausüben. Somit wurde es dringlich, zu gewährleisten, dass die multinationalen Firmen sich überall in der Welt und insbesondere in den Entwicklungsländern in gleicher Weise verhalten.

Im Kapitel II - «Allgemeine Grundsätze» - wird das Konzept der nachhaltigen Entwicklung diesmal als ein Ziel festgesetzt, das die multinationalen Unternehmen anstreben sollen, indem sie zum «wirtschaftlichen, sozialen und ökologischen Fortschritt» beitragen. Ebenfalls neu ist der ausdrückliche Hinweis auf die Achtung der Menschenrechte sowie eine «not lowering standard»-Bestimmung. Diese fordert die multinationalen Unternehmen auf, davon abzusehen, eine Investition in einem Land von der Erlangung von Ausnahmeregelungen bei der Anwendung des geltenden Rechts in den Bereichen Umwelt, Sozialschutz, Gesundheit, Beziehungen zu den Arbeitnehmern und Besteuerung abhängig zu 
machen. Dies ist ein bedeutender Schritt hin zur Anerkennung einer globalen Verantwortung der multinationalen Unternehmen gegenüber den Ländern, in denen sie ihre Aktivitäten ausüben.

Kapitel III - «Offenlegung von Informationen» - wurde den neuen «OECDGrundsätzen über Corporate Governance ${ }^{9}$ angepasst. Diese Leitlinien halten die multinationalen Unternehmen dazu an, regelmässig verlässliche und relevante Informationen über ihre Geschäftstätigkeit, Struktur, Finanzlage und ihre Ergebnisse zu veröffentlichen. Ferner werden sie ermuntert, zusätzliche Informationen über die Ethik-, Sozial- und Umweltpolitik des Unternehmens mitzuteilen. Hingegen kommen sie weiterhin in den Genuss einer Ausnahmeklausel, insofern als sie «Kosten, Vertraulichkeitserfordernisse oder sonstige Wettbewerbserwägungen » anführen können, um sich der Transparenzpflicht zu entziehen.

Kapitel IV - «Beschäftigung und Beziehungen zwischen den Sozialpartnern», eines der wichtigsten Kapitel der «Leitsätze» - wurde wesentlich verbessert. Mit der Hinzufügung von Empfehlungen bezüglich der Abschaffung der Kinder- und Zwangsarbeit sind hinfort alle international anerkannten grundlegenden Arbeitsnormen durch die «Leitsätze» abgedeckt. Man mag jedoch bedauern, dass der Text nicht ausdrücklich die schlimmsten Formen der Kinderarbeit verbietet, gemäss dem IAO-Übereinkommen über die Kinderarbeit in ihrer inakzeptabelsten Form, das am 17. Juni 1999 von der internationalen Staatengemeinschaft einstimmig verabschiedet wurde. Laut IAO-Definition umfassen die schlimmsten Formen der Kinderarbeit alle Formen von Sklaverei oder analogen Praktiken, wie zum Beispiel den Verkauf von Kindern oder den Kinderhandel, den Schuldendienst und die Leibeigenschaft, die Zwangsarbeit oder die obligatorische Arbeitsleistung sowie alle Arbeiten, welche die Gesundheit, die Sicherheit oder die Sittlichkeit von Kindern gefährden können. Das IAO-Übereinkommen hält die Staaten, die dieses Übereinkommen ratifizieren, dazu an, Sanktionen gegenüber den Urhebern solcher Verstösse zu verhängen ${ }^{10}$. Es wäre sehr wünschenswert gewesen, dass die «Leitsätze» ihrerseits diesen weltweiten Kampf für die Achtung der Unversehrtheit und Würde der Kinder bei der Arbeit übernommen hätten.

Kapitel V - «Umwelt» - hält die multinationalen Unternehmen künftig dazu an, ihr Umweltverhalten durch Massnahmen wie besseres internes Umweltmanagement und strengere Regeln betreffend die Veröffentlichung von Umweltinformationen zu verbessern. Der Text führt auch das Vorsorgeprinzip für die Umwelt und die menschliche Gesundheit ein. Ein ehrgeizigerer Entwurf, der das Umweltmanagment als eine Priorität für die multinationalen Unternehmen präsentierte, forderte eine regelmässige Berichterstattung über die ökologischen Leistungen und führte das Prinzip der öffentlichen Beteiligung bei Aktionen an, die Auswirkungen auf die Umwelt haben können. Dieser Entwurf wurde jedoch durch den heftigen Widerstand der Wirtschaftsvertreter beiseite gefegt.

Mit den Kapiteln VI und VII wurden zwei neue Themen - «Bekämpfung der Korruption» und «Verbraucherinteresssen» - in die «Leitsätze» eingeführt. Diese Hinzufügungen wurden von den NRO begrüsst, besonders von jenen

9. OECD-Grundsätze über Corporate Governance, April 1999.

10. «La Convention sur les pires formes de travail des enfants, in "Travail" », Le Magazine de l'OIT, No 30, Juli 1999. 
Organisationen, die in den beiden Bereichen tätig sind und durch ihre Lobbyarbeit weitgehend zu dieser - ursprünglich nicht vorgesehenen - Anpassung beigetragen haben.

\section{SCHWÄCHEN BEI DER UMSETZUNG DER «LEITSÄTZE»}

Insgesamt wurden diese sachlichen Änderungen von allen Nichtregierungsorganisationen, die am Revisionsprozess beteiligt waren, positiv aufgenommen, jedoch mit einigen Vorbehalten. Die Organisationen hätten sich nämlich strengere Formulierungen gegenüber den multinationalen Unternehmen gewünscht und haben bedauert, dass die OECD-Mitgliedsländer sich oft auf die Mindestnormen beschränkt haben. Die Hauptkritik der NRO gegenüber dieser neuen Version der «Leitsätze» betrifft jedoch deren Umsetzung - die nicht nur nicht gewährleistet ist, sondern auch keiner unabhängigen Kontroll- und Evaluationsmassnahme unterzogen wird. Diese Schwäche wirft das Problem der Relevanz und der Glaubwürdigkeit der Empfehlungen auf. Darum traten die NRO im gesamten Verlauf der Verhandlungen für die Annahme eines leistungsfähigeren Umsetzungsmechanismus ein sowie für einen Ausbau der nationalen Kontaktstellen, die mit der Förderung der «Leitsätze» in den Mitgliedsländern beauftragt sind.

Die nationalen Kontaktstellen haben effektiv eine zentrale Rolle zu spielen. Sie sind dafür verantwortlich, die Informationen bei den multinationalen Unternehmen und in der Geschäftswelt zu verbreiten. Sie fungieren auch als Auskunftsstelle für alle Fragen im Zusammenhang mit den «Leitsätzen» und ihrer Anwendung. Die neue Fassung der «Leitsätze» hat die Rolle und die Verantwortungen der nationalen Kontaktstellen verstärkt und präzisiert. Insbesondere das Verfahren zur Beilegung von Streitigkeiten, die bei der Auslegung der «Leitsätze» auftreten können, wurde geklärt, um einen für alle Parteien gerechten und neutralen Verfahrensablauf zu garantieren. Fortan kann eine nationale Kontaktstelle beispielsweise ihre guten Dienste zur Beilegung eines Streitfalls anbieten und wird zu diesem Zweck ermuntert, nicht nur die Beratung der Wirtschaftskreise, sondern auch der Gewerkschaftsorganisationen, der NRO oder anderer Experten heranzuziehen. Ausserdem wurden jährliche Treffen und ein jährlicher Tätigkeitsbericht der Kontaktstellen vorgesehen, um einen besseren Informationsumlauf zu gewährleisten.

Die Schwäche des Umsetzungsprozesses ergibt sich aus der sehr unterschiedlichen Funktionsweise der nationalen Kontaktstellen je nach den einzelnen Ländern und aus dem Fehlen eines jeglichen internationalen Kontroll- und Evaluationsmechanismus. Die Wirksamkeit des Systems beruht fast ausschliesslich auf der Bereitwilligkeit der Regierungen, die Verbreitung der Empfehlungen bei den multinationalen Unternehmen aktiv vorzunehmen und die sich möglicherweise ergebenden Konflikte auf transparente und effiziente Art zu bewältigen. Die OECD-Erklärung von 1976, deren Bestandteil die «Leitsätze» sind, hat keine rechtlich bindende Kraft. Sie ist eine Rechtsurkunde, die vom OECD-Ministerrat angenommen wurde, aber keiner Ratifizierung seitens der Mitgliedsstaaten bedarf. Somit kann jedes Land seiner Verpflichtung den von ihm gewünschten Stellenwert beimessen. Bis heute gibt es keine ausführliche Evaluation des Umsetzungsgrades der «Leitsätze». Jedoch bestehen gute Gründe zur Annahme, dass dieser sehr gering ist. Der Gewerkschaftliche Beratungsausschuss bei der OECD (TUAC) hat dies anlässlich einer der ersten Konsultatio- 
nen zur Überprüfung der «Leitsätze» vom Dezember 1997 unterstrichen : «Die Revision sollte sich auf die Umsetzung und Förderung der Leitsätze konzentrieren, die in vielen Mitgliedsländern der OECD nicht existiert» 1 .

Die nationalen Kontaktstellen sind prinzipiell bei den staatlichen Verwaltungen lokalisiert. In der Schweiz beispielsweise ist die nationale Kontaktstelle der Fachbereich des seco "Investitionen und internationales Wirtschaftsrecht». Bislang ist die Verbreitung der Empfehlungen bei den multinationalen Unternehmen in relativ dürftiger Weise erfolgt. Sie bestand hauptsächlich in der Verteilung der von der OECD erstellten Broschüre an alle betroffenen Wirtschaftsverbände und in der Abhaltung einiger Konferenzen. Die oben erwähnte Liaisongruppe hat dem seco auch als eines der Transmissionsinstrumente zur Informationsverbreitung bei den multinationalen Unternehmen in der Schweiz gedient.

Diese unbefriedigende Situation betreffend die Umsetzung der «Leitsätze» brachte die NRO dazu, die Annahme eines neutralen, unabhängigen und offenen Kontrollverfahrens zu fordern. Sie reichten insbesondere einen Vorschlag ein, der zwei Punkte umfasste: Erstens die Schaffung eines freiwilligen Beitrittsmechanismus für die Unternehmen, die bereit sind, sich offen zur Einhaltung der «Leitsätze» zu verpflichten. Zweitens die Einführung eines öffentlichen Schlichtungsverfahrens, das es jeder betroffenen Partei oder Person erlaubt hätte, eine Klage gegen eines der Unternehmen einzureichen, welches sein Engagement öffentlich erklärt hätte. Indem man den multinationalen Unternehmen hierdurch die Möglichkeit geboten hätte, ihre Bemühungen bei der öffentlichen Meinung zur Geltung zu bringen, wären diese Umsetzungs- und unabhängigen Kontrollmassnahmen ein gutes Mittel zur Motivierung jener Unternehmen gewesen, die sich für die nachhaltige Entwicklung einsetzen wollten. Sie hätten auch die Glaubwürdigkeit der «Leitsätze» bei der Zivilgesellschaft und den NRO erheblich gestärkt.

Diese Vorschläge stiessen jedoch auf heftigen Widerstand. Der Beratende Ausschuss der Wirtschaft bei der OECD (BIAC) war der Ansicht, dass ein solcher Mechanismus einen unter Berücksichtigung der Anzahl der betroffenen Unternehmen zu umfassenden und kostspieligen Bürokratieaufwand erfordern würde. Zudem wären die multinationalen Unternehmen, die sich öffentlich zur Einhaltung der «Leitsätze» verpflichtet hätten, nach Ansicht des BIAC nicht sehr zahlreich gewesen, was die «Leitsätze» um ihren globalen Charakter gebracht hätte. Die Sanktionen des Marktes - das heisst der Verbraucher - wären weitaus genügend, um die multinationalen Unternehmen zu einem korrekten Vorgehen anzuhalten. Einige Entwicklungsländer haben ebenfalls Vorbehalte geäussert. Mexiko hätte sogar beinahe die Annahme der neuen «Leitsätze» verzögert, da seine Vertreter befürchteten, dass die Umwelt- und Sozialbestimmungen sowie das verbesserte Umsetzungsverfahren die Attraktivität ihres Landes für die nordamerikanischen Investoren gefährden könnten. Erst unter dem Druck der übrigen Mitglieder, die auf keinen Fall erneut Verhandungen aufnehmen wollten, und nachdem Mexiko alle Garantien erhalten hatte, dass die «Leitsätze» effektiv keinen rechtsverbindlichen Charakter haben, gab das Land schliesslich seine Zustimmung zur Revision.

11. Engl. Originalfassung: «The Review should focus on the implementation and promotion of the Guidelines which in many Member countries of the OECD is non-existent ». 
Die revidierte Fassung der «Leitsätze» ist eine Anerkennung der Tatsache seitens der OECD-Staaten, dass eine neue Partnerschaftsform zwischen Regierungen und multinationalen Unternehmen notwendig ist, um die Unternehmen dazu zu bringen, ihre Verantwortung bei der Förderung der nachhaltigen Entwicklung zu übernehmen. Die Globalisierung der Wirtschaft, die durch die Liberalisierung des Handels und die Deregulierungen gekennzeichnet ist, hat die Art der Beziehungen zwischen den multinationalen Unternehmen und den Staaten radikal verändert. Der Abbau der Grenzen hat eine neue Priorität zutage treten lassen, nämlich den wirtschaftlichen Akteuren einen Funktionsrahmen mit globalen und ausgewogenen Rechten und Verantwortungen zu bieten, die dem Kontext eines integrierten Weltmarktes entsprechen. Eine Regulierung des Verhaltens der multinationalen Unternehmen kann nicht mehr nur gegenüber den Staaten erfolgen, sondern es müssen von jetzt an auch neue weltweite soziale und umweltbedingte Besorgnisse unbedingt berücksichtigt werden.

Mit dem Multilateralen Abkommen über Investitionen wollte die OECD damit anfangen, den Investoren Rechte zu garantieren, ohne dabei den Pflichten die gleiche Bedeutung beizumessen. Diese Strategie ist dank der Wachsamkeit der Zivilgesellschaft gescheitert, der sich die NRO der ganzen Welt angeschlossen haben. Mit der Annahme der neuen «Leitsätze» steht man vor dem ersten multilateralen Verhaltenskodex, der die international anerkannten sozialen und ökologischen Mindestnormen ausdrücklich anführt. Diese Normen bilden folglich eine erste offizielle Bezugnahme in diesem Bereich, welche sich bei der Ausarbeitung anderer Anreizinstrumente als besonders nützlich erweisen könnte, wie zum Beispiel die zahlreichen privaten Verhaltenskodizes, die von den multinationalen Unternehmen vor kurzem einseitig oder in Zusammenarbeit mit NRO ausgearbeitet wurden.

Obwohl die Wirksamkeit und der Nutzen der «Leitsätze» wegen ihres rechtlich nicht bindenden Charakters nicht wirklich garantiert werden können, stellen die «Leitsätze» in der Tat insofern einen ersten Ansatz von Verpflichtungen dar, als die Unterzeichnerstaaten akzeptiert haben, sie bei ihren multinationalen Unternehmen zu fördern. Da die Problematik, wie wir oben gesehen haben, letztendlich weniger im rechtlich nicht bindenden Charakter der Empfehlungen als in der Art ihrer Umsetzung liegt, kann man hoffen, dass diesem Schritt in die richtige Richtung bald andere Schritte folgen werden. Die Mitgliedsstaaten der OECD haben nämlich beschlossen, die Diskussionen über die Verbesserung des Konkretisierungsprozesses fortzusetzen. Sie wollen ihre Bemühungen insbesondere auf die Frage der grösstmöglichen Verbreitung der «Leitsätze» und auf die Intensivierung der Kontakte mit den Nichtmitgliedsländern der OECD konzentrieren. Die geographische Ausdehnung des Anwendungsbereichs der «Leitsätze» auf die gesamte Welt wirft effektiv zusätzliche Probleme bei der Umsetzung auf - vor allem wegen des Fehlens nationaler Kontaktstellen in den Nichtmitgliedsstaaten der OECD - für die angemessene Lösungen gefunden werden sollen.

Im Übrigen ist die Bemühung der OECD zu begrüssen, transparent und offen vorzugehen. Die NRO konnten nicht nur aktiv am Revisionsprozess teilnehmen, sondern sie werden von jetzt an ausdrücklich als Partner im Rahmen der verschiedenen Konsultationsmechanismen anerkannt, die auf der Ebene des 
OECD-Ausschusses für internationale Investitionen und multinationale Unternehmen (CIME) und der nationalen Kontaktstellen vorgesehen sind. Somit können sie hinfort gleichberechtigt mit den Wirtschafts- und Gewerkschaftskreisen jederzeit Konsultationen auf internationaler und nationaler Ebene beantragen. Die Aufmerksamkeit, die die «Leitsätze» weiterhin bei der Zivilgesellschaft erregen werden, wird folglich zweifellos ein Ansporn dafür sein, dass die «Leitsätze» zu einem wirklichen Förderungsinstrument für ein verantwortungsbewusstes Verhalten der multinationalen Unternehmen gegenüber dem wirtschaftlichen, sozialen und ökologischen Kontext werden, in dem sie sich entwickeln.

\section{QUELLEN}

«Les «Principes directeurs» de l'OCDE dans un monde en voie de mondialisation », Arghyrios A. Fatouros, überarbeitete Version eines Dokuments, das vom Verfasser an der Konferenz von Budapest über die «OECD-Leitsätze» im November 1998 unterbreitet wurde und von der Direktion der OECD für Finanz-, Steuer- und Unternehmensfragen veröffentlicht wurde.

«Mexiko digs in over OECD rules », Guy de Jonquières, Financial Times, 23. Juni 2000.

«OECD Revising Guidelines for Multinationals, Environment, Labor Standards Prominent », Lawrence J. Speer, in International Trade Reporter, Volume 17, Nr. 5, 3. Februar 2000, S. 193. Internet-Adresse der OECD: www.oecd.org.

Die «OECD-Leitsätze für multinationale Unternehmen» können unter der Internet-Adresse www.oecd. org/deutschland eingesehen werden. 
Peter UtTing*

\section{EINFÜHRUNG}

$\mathrm{Zu}$ den Entwicklungsorganisationen und den Akteuren, die sich mit der Förderung der nachhaltigen Entwicklung ${ }^{13}$ befassen, gesellten sich in jüngster Vergangenheit andere Kräfte - das «Big business» oder Grosskapital. Dass auch höhere Manager zunehmend auf Konzepte wie «Corporate citizenship» (Bürgersinn der Unternehmen) oder «Corporate social responsibility (soziale Verantwortung der Unternehmen) setzen, legt die Annahme nahe, dass der Sektor sein Verhältnis zur Umwelt und zu den verschiedenen Anspruchsgruppen neu definiert. Die sich abzeichnende Entwicklung steht in krassem Gegensatz zum Szenario der Vergangenheit, als das Grosskapital als wenig aufgeschlossen für die Bedürfnisse der Anspruchsgruppen und als hauptverantwortlich für die Umweltzerstörung auf dem Planeten galt.

In der vorliegenden Studie soll untersucht werden, inwieweit grosse Firmen Massnahmen und Praktiken zur Förderung der nachhaltigen Entwicklung verabschieden. Nach der Beschreibung verschiedener institutioneller Entwicklungen, welche die soziale und ökologische Verantwortung zu fördern scheinen, widmet sich die Studie ihren Auswirkungen und prüft, ob mit einer signifikanten Verbesserung der sozialen und ökologischen Leistungen der Grosskonzerne zu rechnen ist.

\section{INSTITUTIONELLE ENTWICKLUNGEN}

In verschiedenen Etappen der Geschichte des Unternehmenskapitalismus verabschiedete das Grosskapital Politiken und Reformen, in denen es um die ökologische und soziale Verantwortung ging. In den ersten Jahrzehnten des zwanzigsten Jahrhunderts zum Beispiel setzten sich mehrere amerikanische Grossindustrielle wie Ford und Carnegie für wohltätige Zwecke ein und ergriffen ausserdem Massnahmen, um an den Standorten ihrer Fabriken die Lebensbedingungen der Arbeitnehmer und der Gemeinschaften zu verbessern. Nach dem Zweiten Weltkrieg, mit dem Einzug der sozialen Demokratie und der Gesetze über den Wohlfahrtsstaat, wurde die soziale Verantwortung der Unternehmen in bestimmtem Ausmass weiterentwickelt. In den Entwicklungsländern wirkten sich diese Tendenzen meistens viel schwächer aus. Verschiedene parastaatliche Unternehmen in Afrika und grosse Familienbetriebe im Fernen Osten jedoch entwickelten bedeutende soziale Politiken.

* Peter Utting: Projektkoordinator, UNRISD, Genf.

12. Beim vorliegenden Text handelt es sich um eine gekürzte Fassung eines für das UNRISD vorbereiteten Dokuments mit dem Titel Business Responsibility for Sustainable Development (Utting, 2000a).

13. Die Brundtland-Kommission definierte die «nachhaltige Entwicklung» wie folgt: "Nachhaltig ist eine Entwicklung, wenn sie die heutigen Bedürfnisse zu decken vermag, ohne für künftige Generationen die Möglichkeiten zu schmälern, ihre eigenen Bedürfnisse zu decken.» (WCED, 1987). Es handelt sich selbstverständlich um eine Grössenordnung, die suggeriert, dass die nachhaltige Entwicklung mehr als Verfahren, weniger als Ziel, betrachtet werden soll. Nach einer anderen Formulierung ist nachhaltige Entwicklung der Prozess, der die Widersprüche zwischen Wirtschaftswachstum, Umweltschutz und sozialer Wohlfahrt möglichst gering hält (Utting, 1993). 
Die gegenwärtige Welle der Unternehmensverantwortung unterscheidet sich in verschiedenen Punkten von der Vergangenheit. Die Auswirkungen sind in mehr Ländern zu verspüren, die Triebkräfte vielfältiger, es herrschen unterschiedliche politische Ansätze und institutionelle Vorkehrungen zur Förderung der Verantwortung der Geschäftswelt vor, und bis vor kurzem standen ökologische Aspekte gegenüber den sozialen im Vordergrund.

Ein Schlüsselereignis in der Geschichte der zeitgenössischen Unternehmensverantwortung war der Rio-Gipfel im Juni 1992, der das Thema Umweltzerstörung und nachhaltige Entwicklung in den Blickpunkt der öffentlichen Meinung und der Unternehmenswelt rückte. Die Agenda 21, der Aktionsplan des Gipfels, enthielt rund 32 Bestimmungen zu den Tätigkeiten der Transnationalen Konzerne (TNK) (UNCTAD, 1996: 3). Die Regierungen der Welt, die Geschäftsgemeinschaft, die internationalen Entwicklungsorganisationen und die Nichtregierungsorganisationen (NRO) sollen sich gemeinsam bemühen, Wirtschaftswachstum und Umweltschutz miteinander $\mathrm{zu}$ vereinbaren. Die auf Konfrontation angelegte Politik früherer Jahrzehnte, bei der Gruppen und Organisationen, die sich für Regelungen und Umverteilung einsetzten, Opposition gegen TNK betrieben, büsste deutlich an Elan ein. Anstelle der staatlichen Regelung wurde nun weithin die «Selbstregulierung der Unternehmen» sowie freiwillige Initiativen als beste Methode befürwortet, um die Annahme von Instrumenten und Verfahren im Zusammenhang mit der ökologischen Verantwortung der Unternehmen voranzutreiben. Dazu gehören beispielsweise Verhaltenskodizes, der Einsatz von saubereren Technologien, Lebenszyklusanalysen ${ }^{14}$, Umweltberichterstattung und die Zertifizierung.

In den 90er Jahren fanden einige entscheidende institutionelle Entwicklungen zur Förderung der ökologischen und sozialen Verantwortung der Unternehmen statt. Die Erklärung von Rio appelliert an die Wirtschaft, in Bezug auf Umweltprobleme den «Vorsorgegrundsatz» 15 zu unterstützen, Initiativen zu Gunsten der ökologischen Verantwortung durchzuführen und die Entwicklung und Verbreitung umweltverträglicher Technologien voranzutreiben (Annan, 1999). Weite Teile der Geschäftswelt, angeführt von einem kleinen Kreis massgeblicher TNK, anerkannten ausdrücklich, dass die Firmen eine Kurskorrektur vornehmen und im Umweltschutz und in der nachhaltigen Entwicklung eine proaktivere Rolle spielen müssen. Der Unternehmensrat für nachhaltige Entwicklung (BCSD), eine Vereinigung von TNK, übte einen entscheidenden Einfluss auf den UNCED-Prozess aus. In Veröffentlichungen wie Changing Course (Schmidheiny, 1992) rief der Sektor zu einem Umdenken in den Unternehmensstrategien über den Einsatz und Umgang mit natürlichen Ressourcen auf und präsentierte eine als «Ökoeffizienz» bekannte Lösung. Die Internationale Handelskammer (IHK) hatte im Jahr 1991 in der Unternehmenscharta für nachhaltige Entwicklung 16 Umweltgrundsätze festgeschrieben und sich auch am Rio-Gipfel beteiligt; nach ihrer Auffassung hat der Unternehmenssektor nun den Weg der nachhaltigen Entwicklung beschritten (Schmidheiny et al., 1997).

14. Bei Lebenszyklusanalysen werden die Umweltauswirkungen bestimmter Produkte oder Dienstleistungen in den einzelnen Produktions-, Vermarktungs- und Entsorgungsphasen untersucht.

15. Gemäss dem Vorsorgegrundsatz sind Massnahmen zum Schutz der Umwelt auch in Situationen angezeigt, in denen die Ursachen und Auswirkungen der Umweltzerstörung nicht mit lückenloser wissenschaftlicher Gewissheit nachgewiesen sind. 
Im Anschluss an den Rio-Gipfel wurde der Prozess der Förderung einer Umweltpolitik der Unternehmen mit dem Aufkommen zahlreicher Geschäftsvereinigungen - so genannter "Green business networks", die ausdrücklich umweltpolitische Ziele verfolgen (Tomorrow, 1994) - beschleunigt. In der zweiten Hälfte der 90er Jahre kam es zur Konsolidierung bestimmter Vereinigungen; am bekanntesten ist wohl die Fusion des BCSD mit dem Weltindustrierat für Umwelt (WICE) im Jahr 1995, aus welcher der Weltunternehmensrat für nachhaltige Entwicklung (WBCSD) hervorging (Hansen, 1999a). Im darauf folgenden Jahr verabschiedete der Internationale Normungsausschuss (ISO) eine allgemeine Normenserie $\mathrm{zu}$ den betrieblichen Umweltmanagementsystemen. Dieser Standardkatalog, als ISO 14000-Serie bekannt, setzt sich allmählich als Referenzwert und Basis für die Zertifizierung zwecks Erleichterung des internationalen Handels durch (UNCTAD, 1996).

Auch neue regionale Institutionen beeinflussen die Politik und Praxis der Unternehmen. Das Ökomanagement- und Auditsystem (EMAS) der Europäischen Union beispielsweise wurde 1993 mit dem Ziel gestartet, das gute Umweltmanagement der Produzenten zu fördern; es stellt eine anspruchsvollere Normenserie dar als ISO 14001. Der NAFTA-Ausschuss für Umweltzusammenarbeit ist für Umweltangelegenheiten in Kanada, den Vereinigten Staaten und Mexiko zuständig. Der Zentralamerikanische Rat für nachhaltige Entwicklung, welchen die Präsidenten der Region im Jahr 1989 einrichteten, setzt sich in sieben Ländern - vor allem in für die Geschäftswelt interessanten Sektoren wie der Forstwirtschaft und dem Tourismus - aktiv für Planung und Projekte zur nachhaltigen Entwicklung ein.

Ausserdem fördern zahlreiche Industrieverbände und einzelne Betriebe so genannte «freiwillige Initiativen». Damit werden die Unternehmen aufgefordert, die Selbstregulierung einzuführen oder mit der Regierung zusammen gemeinsam vereinbarte Standards auszuhandeln und umzusetzen. Die bekanntesten Beispiele für freiwillige Initiativen sind verschiedene Verhaltenskodizes oder Leitlinien der internationalen und nationalen Industrieverbände. Dazu gehören unter anderem die zahlreichen «Responsible Care»-Initiativen der nationalen Chemieverbände, welche die Mitgliedsunternehmen verpflichten, die Aspekte Arbeitsschutz und Umwelt kontinuierlich $\mathrm{zu}$ verbessern (IAO, 1999) ${ }^{16}$, sowie die 1991 geschaffene «Globale Umweltcharta von Keidanren», welche an Unternehmen in Japan appelliert, auf eine gesunde menschliche, ökologische und ökonomische Umwelt hin zu arbeiten (UNCTAD, 1996: 148). Mitte 1999 hatten 2'300 Unternehmen - knapp ein Drittel der Mitglieder der Organisation - die IHK-Charta angenommen. ${ }^{17}$

In der zweiten Hälfte der 90er Jahre setzten sich die Grosskonzerne immer eingehender mit Fragen der sozialen Unternehmensverantwortung auseinander. Die Unternehmensvereinigung für den Weltsozialgipfel (BUSCO) gab anlässlich der Konferenz von Kopenhagen im Jahr 1995 eine Grundsatzerklärung ab und legte ein Aktionsprogramm in 16 Punkten vor, das die Unternehmen umsetzen sollen, um ihren Beitrag an den sozialen Fortschritt zu verstärken (BUSCO, 1995). Organisationen wie der WBCSD diversifizierten ihre Tätigkeiten und setzten

16. 1996 hatten ungefähr 40 nationale Verbände von Chemieproduzenten, deren Mitglieder 86 Prozent des weltweiten Produktionsvolumens ausmachen, die «Responsible Care »-Initiative angenommen.

17. Persönliches Gespräch mit einem IHK-Beamten, 17. August 1999. 
sich unmittelbar mit den Themen der sozialen Unternehmensverantwortung auseinander (Watts und Holme, 1999). Im Jahr 1997 verabschiedeten internationale Industrieorganisationen wie der Weltverband der Sportartikelindustrie und der Internationale Rat der Spielwarenindustrie verschiedene Kodizes, die sich insbesondere mit den Arbeitsbedingungen und mit der Kinderarbeit befassten (Wild, 1998).

In jüngster Vergangenheit haben auch private Betriebe ihre Kodizes oder Leitlinien um Verpflichtungen in Bezug auf die Menschenrechte ergänzt und erweitert. Im Jahr 1997 zum Beispiel überarbeitete Shell seine Allgemeine Geschäftsgrundsatzerklärung, um den Grundsätzen der Allgemeinen Erklärung der Menschenrechte der Vereinten Nationen Geltung zu verschaffen. (UNCTAD, 1999). Die Unternehmen beteiligten sich ausserdem am Entwurf von "Social Accountability (SA) 8000 », einem vom Rat der Akkreditierungsstelle für wirtschaftliche Prioritäten (CEPAA) ${ }^{18}$ im Jahr 1998 entwickelten Standard. SA 8000 beruht auf verschiedenen völkerrechtlichen Normen der IAO und der UNO zu Arbeitsbedingungen und Menschenrechten und bezweckt die Verbesserung der Lebens- und Arbeitsbedingungen der Anspruchsgruppen von Unternehmen in Entwicklungs- und Industrieländern (Wild, 1998).

Eine weitere internationalen Initiative, die Ende der 90er Jahre lanciert wurde, zeugt von dem Bewusstsein der Unternehmen für ökologische und soziale Aspekte: Bei der Globalen Berichterstattungsinitiative (GRI) handelt es sich um das Vorhaben verschiedener Anspruchsgruppen, einen gemeinsamen Rahmen für die freiwillige Berichterstattung über die wirtschaftlichen, umweltbezogenen und sozialen Auswirkungen der Firmentätigkeit zu schaffen. ${ }^{19}$ Die Entwürfe der GRI-Leitlinien wurden 1999 von 21 Unternehmen in Pilotversuchen getestet.

Das Umdenken in der Geschäftswelt äussert sich ebenfalls im Aufkommen der «Partnerschaften ». In den letzten zehn Jahren wurde eine merkliche Annäherung zwischen den Grosskonzernen und bestimmten Akteuren beobachtet - darunter Regierungen, Organisationen der UNO und einige NRO, die in der Vergangenheit die Unternehmenstätigkeiten durch richtliniengestützte Massnahmen, internationale Verhaltenskodizes und durch Konfrontationspolitik zu beeinflussen versuchten. Heute streben viele von ihnen eine Zusammenarbeit mit der Geschäftswelt an.

Einige global führende Konzerne bemühen sich aktiv um Partnerschaften mit NRO und den Organisationen der Vereinten Nationen. Ein Überblick über den Stand des «Green Business» aus dem Jahr 1998 hält fest, dass sich für zukunftsgerichtete Unternehmen Partnerschaften rasch als Königsweg herausgestellt hätten (Frankel, 1999: 11). In den letzten Jahren sind zahlreiche hochkarätige Partnerschaften entstanden. 1996 zum Beispiel schloss der WWF-International eine Partnerschaft mit Unilever Corporation, dem weltweit wichtigsten Abnehmer von Gefrierfisch, ab, um in der Meeresfrüchtebranche überall auf der Welt wirtschaftliche Anreize für die «nachhaltige Fischerei » zu schaffen. Als Ergebnis der Bemühungen wurde der Marine Verwaltungsrat (MSC) gegründet. Die Fairtrade Foundation - eine Koalition von internationalen Entwicklungs-,

18. Im Jahr 2000 wurde CEPAA in «Social Accountability International » umbenannt.

19. Die GRI wurde im Jahr 1997 von der Koalition für umweltverantwortliche Wirtschaften (CERES) und dem Umweltprogramm der Vereinten Nationen (UNEP) einberufen. Bis 2002 soll die GRI als unabhängiges Organ eingesetzt werden. 
Umwelt- und Fairer Handel-Organisationen - will in einem Pilotprojekt mit britischen Unternehmen zusammen Kodizes zu Praktiken erarbeiten, die das Verhältnis zu den südlichen Zulieferern bestimmen sollen. Im Jahr 1998 schloss sich British Petroleum mit dem Umweltschutzfonds zusammen und General Motors mit dem Weltressourceninstitut. Ende 1998 unterstützten rund 17 Unternehmen von Fortune 500 das Pew Center on Global Climate Change (Frankel, 1999).

Während die Zusammenarbeit zwischen NRO und der Geschäftswelt in der Vergangenheit oft von der Wohltätigkeit ausging, wirken heute zahlreiche NRO in innerbetrieblichen Abläufen der Unternehmen mit (Murphy und Bendell, 1999) - zum Beispiel in der Ausarbeitung von Verhaltenskodizes, der Entwicklung von Umweltberichterstattungssystemen oder der Durchführung unabhängiger Sozialaudits. Das Verhältnis der NRO zur Geschäftswelt beruht auf der so genannten «zivilen Regulierung», welche den Geschäftssektor unter Zugzwang setzt, nicht nur die eigenen Standards (Selbstregulierung der Unternehmen) oder jene der Regierungen (Befolgung der Gesetze), sondern auch teilweise von den Institutionen der Zivilgesellschaft definierte Normen und Standards zu erfüllen (Murphy und Bendell, 1999).

Auch die Anzahl Partnerschaften zwischen dem Geschäftssektor und Organisationen der Vereinten Nationen (wie UNCTAD, UNEP, UNIDO und WHO) hat in den letzten Jahren deutlich zugenommen (Tesner, 1999; Utting, 2000b). 1999 schloss sich die IHK dem Appell des UN-Generalsekretärs Kofi Annan für einen Pakt zwischen den Vereinten Nationen und der Privatwirtschaft an ; Unternehmen sollen sich in den Bereichen Umweltschutz, Arbeitsbedingungen und Menschenrechte freiwillig an die Standards der Vereinten Nationen halten und zu diesem Zweck mit UN-Organisationen zusammenarbeiten. Der «Global Compact» wurde im Juli 2000 offiziell proklamiert. Ziel ist, in einer Dreijahresfrist die Unterstützung von 100 Grosskonzernen und insgesamt 1000 Unternehmen zu gewinnen.

\section{BEDEUTENDER WANDEL?}

Welche Bedeutung besitzen diese Tätigkeiten für die Förderung der nachhaltigen Entwicklung im Süden? Reichen die zahlreichen Initiativen der Geschäftswelt aus, um die Trägheit des gegenwärtigen Destruktionskurses zu überwinden und einen neuen Elan für die nachhaltige Entwicklung zu schaffen (Schmidheiny, 1992)? Die Meinungen hierzu gehen oft sehr stark auseinander.

Der WBCSD vertritt die Auffassung, dass trotz der in puncto Tempo und Ort noch ungleichen Veränderungen (Schmidheiny et al., 1997) verschiedene Veränderungen in der Politik und Praxis der Unternehmen auf einen «Paradigmawechsel» hindeuten :

- von der Gleichsetzung des Konzeptes nachhaltige Entwicklung mit Kosten und Problemen zur Erkennntis, dass damit auch Einsparungsmöglichkeiten und Chancen verbunden sind;

- von Ansätzen, die am Ende der Kette gegen die Verschmutzung vorgehen, zum durchgängigen Einsatz saubererer und effizienterer Technologien in den Produktionssystemen und zur Betrachtung der nachhaltigen Entwicklung als fester Bestandteil der Unternehmensentwicklung; 
- von linearem «Durchsatz»-Denken und Ansätzen zu System- und Recycling-Ansätzen;

- von der Betrachtung der ökologischen und sozialen Fragen als ausschliessliche Aufgabe der technischen Abteilungen oder Experten zur Betrachtung dieser Themen als unternehmensweite Verantwortungen;

- vom Grundsatz der Geheimhaltung zu Offenheit und Transparenz;

- von Lobbying hinter den Kulissen zu offeneren Diskussionen mit den Anspruchsgruppen.

Gemäss dieser Perspektive führen die Unternehmen nicht nur vermehrt Innovationen im Betriebsumfeld und im Bereich der sozialen Verantwortung ein, sondern sie verabschieden sich von engstirnigen, lückenhaften und technischen Ansätzen und wenden sich einer holistischen, systemischen Haltung zu, die auf die vielfältigen Anspruchsgruppen eingeht.

Dieser Position widersprechen jene, die den Unternehmen vorwerfen, Fassadenpflege zu betreiben oder sich «grün zu waschen». Nach Ansicht von Corporate Watch versuchten Unternehmen mit sozial und ökologisch gefährlichen Praktiken, ihre Märkte zu schützen und auszudehnen, indem sie sich als Freunde der Umwelt und führende Kräfte in der Armutsbekämpfung ausgeben (Corporate Watch, 1996). Viele Unternehmenspolitiken seien inhaltsarm oder würden nicht verwirklicht, und im Grunde würde nur an einem System herumgeschustert, welches das «Business-as-Usual» ermutigt (Welford, 1997).

In der Praxis lässt sich der aktuelle Sachstand betreffend die ökologische und soziale Verantwortung der Unternehmen nur sehr schwer beurteilen. In der Fachliteratur wird regelmässig und beharrlich vorgebracht, die «Beweise» stammten aus einer Handvoll Anekdoten und Fallstudien und/oder groben Verallgemeinerungen zum Verhalten der Firmen vor dem Hintergrund des Kapitalismus und der Globalisierung. Besondere Verwirrung stiftet die Tatsache, dass etliche Unternehmen, deren «beste Praktiken» gelobt werden, gleichzeitig als Unternehmen mit schlechten Praktiken bezeichnet werden (siehe Kasten). In nur wenigen Untersuchungen wird versucht, zu quantifizieren, wie viele Unternehmen ihre ökologische und soziale Leistung verbessert haben; zudem werden in der Regel Veränderungen in Unternehmenspolitik und Verfahren, nicht aber die ökologischen und sozialen Auswirkungen, gemessen.

Dagegen stimmen die meisten Beobachter überein, dass die Unternehmensverantwortung in ihrer heutigen Form eine uneinheitliches und ungleiches Bild abgibt. Nur sehr wenige Unternehmen sind auf diesem Gebiet in Führung gegangen. Hawken schrieb in den frühen 90er Jahren, dass die rund 2'000 engagierten Unternehmen einen Jahresumsatz von schätzungsweise 2 Milliarden Dollar erwirtschafteten - ein Hundertstel Prozent des Umsatzes von 20 Billionen Dollar, den die rund 80 bis 100 Millionen Unternehmen weltweit einfahren (Hawken, 1993, zitiert in Thomson, 1998). Seit dieser Schätzung haben sich einige der allergrössten Konzerne der Welt der Bewegung der Unternehmensverantwortung angeschlossen. Allerdings machen die Beteiligten nach wie vor einen kleinen Bruchteil der insgesamt 63'000 TNK aus (UNCTAD, 2000). In den meisten Fällen sind zudem nur begrenzte Tätigkeitsbereiche betroffen.

Die wohl prominenteste Geschäftsvereinigung in diesem Bereich ist der WBCSD mit zwar nur 120 Mitgliedern, zu denen aber einige der grössten TNK zählen. Die Illusion eines tiefer greifenden Wandels rührt teilweise daher, dass 
die beteiligten TNK und die Geschäfts- oder Industrieverbände zu den Schwergewichten in der internationalen Arena gehören und dass sie für ihre neue Politik in den Medien, in der Konzernwerbung, in Veröffentlichungen, auf Konferenzen und in internationalen Institutionen sehr aktiv die Werbetrommel rühren. Mit ein Grund ist die Fülle von Fachliteratur zu den «besten Praktiken » und zu den Massnahmen und Gepflogenheiten der relativ wenigen Unternehmen, die in Sachen Unternehmensverantwortung eine Führungsrolle übernommen haben. Bisweilen werden solche Informationen irreführend als repräsentativ für die breitere Unternehmenswelt ausgelegt. ${ }^{20}$

Das begrenzte Ausmass des Wandels wird unten dargestellt (der Schwerpunkt liegt hauptsächlich auf den Entwicklungsländern) und lässt sich wie folgt zusammenfassen: nur rudimentäre Veränderungen in der Politik und den Prozeduren der Unternehmen; eine tiefe Kluft zwischen Worten und Taten; das vorherrschende Modell des Wirtschaftswachstums leistet nach wie vor Geschäftspraktiken Vorschub, welche die Umwelt zerstören und die Anliegen verschiedener Anspruchsgruppen missachten (Utting, im Druck).

\section{Box: Best or Bad Practice?}

Asea Brown Boveri (ABB), the Swedish/Swiss engineering corporation, is an active member of the WBCSD. It is "a world leader in developing eco-efficient technologies in a wide range of industry areas from electricity transmission to transportation, and is building a global network of joint ventures and strategic alliances to install these technologies in many developing and transition economies" (Nelson, 1996 : 163). ABB has also "faced sustained campaigns by environmentalists and human rights advocates against its involvement in various hydro projects, including the Three Gorges Project in China and the now indefinitely postponed Bakun Dam in Malaysia" (TRAC, 1999 : 1).

Aracruz Celulose, the world's largest exporter of bleached-eucalyptus pulp, is often cited for its efforts to promote sustainable development through its tree planting, harvesting and pulp production processes in Brazil (Sargent and Bass, 1992). "Since its establishment, the company has earned a positive reputation both nationally and internationally for its efforts to incorporate social and environmental factors into its corporate vision" (Nelson, 1996 : 202). Certain investigations, however, have revealed a very different picture: "... its eucalyptus trees have dried streams, destroyed the local fauna, impoverished the soil, impeded the regrowth of native plant species, and drastically reduced the area available for cultivating basic foodstuffs ... This is not to mention land concentration and the expulsion of the rural population ..."(Goncalves et al., 1994, quoted in Carrere, 1999)

Dow Chemical is a US corporation which was selected to participate in one UN-business partnership for, inter alia, "abid[ing] by the highest standards of human rights, environmental and labor standards and norms, as defined by UN agencies" (UNDP, 1999a). According to the Transnational Resource and Action Center (TRAC) "... Dow Chemical is probably the world's largest root source of dioxin - a chlorine by-product closely associated with reproductive disorders, birth defects, increased rates of cancer, and endocrine disruption. ... Dow has regularly exported pesticides unregistered in the U.S. for use in developing countries." (TRAC, 1999)

General Motors (GM), the world's largest automobile manufacturer, is involved in various environmental protection initiatives and partnerships. It is a Charter Partner to the Climate Wise Program, promoted by the US government to encourage energy efficiency (WBCSD, 1999 : 13), and in 1998 entered into a partnership with the World Resources Institute to "define a long-term vision for protecting the earth's climate and the technologies and policies for getting there" (WRI, 1998). Simultaneously, however, GM "maintained its membership in the hardline [Global Climate Coalition] ... [which] continued to be a bastion of reaction and misinformation ..., and the Business Roundtable, which opposes the Kyoto Protocol ..." (Frankel, 1999 : 11).

20. In einer Untersuchung mit einer niedrigen Rücklaufquote zu TNK-Tochtergesellschaften in drei asiatischen Ländern wird vor solchen Fehldeutungen gewarnt (Hansen, 1996). 
Mitsubishi Group, has been actively cultivating an image of environmental responsibility through advertising and specific environmental projects. At the same time, it is reputed to be "a leading destroyer of tropical (and non-tropical) forests" (Greer and Bruno, 1996 : 182). In spring 1998, Mitsubishi was a recipient of the Corporate Watch award for companies excelling in greenwash. In Mexico, the corporation has come under fire for its plans to vastly expand salt production in Baja California, which would have potentially serious implications for a local biosphere reserve, fishing communities and conflicts over land tenure and scarce natural resources such as water (Barkin, 1999).

Novartis, the Swiss life science corporation, is another member of the WBCSD. It is often cited for its efforts in the fields of poverty alleviation and environmental protection. In 1992, for example, the company established a five-year programme to reduce the environmental and social impacts of pesticide use in the Dominican Republic (Watts and Holme, 1999: 16), and the Novartis Foundation has been active in the field of corporate philanthropy (Novartis, 1998). Despite company claims to be committed to "sustainable development", however, there are concerns that the fundamental Precautionary Principle, which business was asked to uphold at the Earth Summit in 1992, is being ignored by virtue of the company's promotion of genetically modified crops.

Rio Tinto, the British mining company, is often cited for its standards of environmental reporting and for promoting "continued social development" and "sustainable livelihood" in areas such as East Kalimantan, where the company's large mines approach closure (Watts and Holme, 1999 : 10). Yet, according to TRAC, the corporation "has created so many environmental, human rights, and development problems that a global network of trade unions, indigenous peoples, church groups, and community activists has emerged to fight its... [alleged] complicity in, or direct violations ... in Indonesia, Papua New Guinea, Philippines, Namibia, Madagascar, the United States and Australia ..." (TRAC, 1999: 1)

\section{$\square$ Zögerliche und unregelmässige Fortschritte}

Bekannte Beispiele von Initiativen im Bereich der Unternehmensverantwortung sind Verhaltenskodizes oder spezifische Grundsatzerklärungen zu Umwelt- und Sozialfragen. Wie oben erwähnt haben eine steigende Anzahl Unternehmen sowie Geschäfts- und Industrieverbände Verhaltenskodizes und Leitgrundsätze erarbeitet.

Trotz der heutigen globalen Welle des Enthusiasmus haben in den meisten Ländern erst relativ wenige Unternehmen solche Kodizes verabschiedet: Laut einer jüngsten diesbezüglichen Bestandsaufnahme der OECD sind es gerade 233 (OECD, 1999 a). Selbst die Entwicklungsländer, in denen grössere Fortschritte zu erwarten wären, weisen keine beeindruckenden Zahlen aus. In Costa Rica zum Beispiel, einem Land, das für verschiedene Umweltschutzinitiativen internationale Anerkennung fand, verfolgt nur ein Drittel der Grossunternehmen eine Umweltpolitik (Pratt und Fintel, 1999). Erschwerend kommt hinzu, dass viele Kodizes nur eine begrenzte Tragweite besitzen. Eine Studie zu kanadischen Konzernen liess beispielsweise ersehen, dass die meisten Grossunternehmen mit Aktivitäten oder Versorgungsquellen im Ausland nicht einmal Verweise auf die grundlegendsten Menschenrechte enthalten (Forcese, 1996). Die Prioritätsthemen der Kodizes sind oft jene, die den Verbrauchern am Herzen liegen - wie Kinderarbeit, Diskriminierung und Umweltschutz - nicht jene, welche internationale Organisationen wie die IAO als Prioritäten identifizierten: Die Vereinigungsfreiheit und das Tarifverhandlungsrecht werden kaum je genannt (Wild, 1998: 32).

Bei der Annahme von Kodizes ist also noch vieles zu leisten. Noch stärker zu wünschen übrig lässt indessen die Umsetzung. Die Kodizes bleiben oft auf dem Niveau von vagen Prinzipien und gut gemeinten Grundsatzerklärungen, die nicht in die Wirklichkeit umgesetzt werden (Kolk et al., 1999). In einer Untersu- 
chung der UNCTAD zu Leitlinien, die 26 globale Industrieverbände für ihre Mitglieder formuliert hatten, wurde festgestellt, dass die meisten Leitlinien die Unterzeichner gar nicht auffordern, sich auf die empfohlenen Grundsätze oder Tätigkeiten zu verpflichten, und dass nur sehr wenige die Einhaltung durch die Mitglieder überhaupt verlangen (UNCTAD, 1996: 7). Oft wissen weder die Beschäftigten noch die Verbraucher, dass Unternehmenskodizes existieren, und die Firmen unterlassen es häufig, über die Art der Sanktionen bei Nichterfüllung $\mathrm{zu}$ informieren. Besondere Besorgnis weckt die Tatsache, dass eine effiziente Selbstbeurteilung durch das Unternehmen oder eine unabhängige Überprüfung der Befolgung von Kodizes kaum stattfindet (Dommen, 1999; IAO, 1999; UNCTAD, 1996). Nach der oben erwähnten kanadischen Studie fehlen in den meisten Kodizes Vorschriften für eine unabhängige Kontrolle; offenbar machen die Unternehmen die Kodizes nur ungern publik, selbst wenn diese angeblich Formulierungen aus den Menschenrechten enthalten. Ihre Zurückhaltung steht in krassem Gegensatz zum Appell der Analysten für mehr Transparenz in der Ausarbeitung, Umsetzung und Verwaltung der Kodizes (Forcese, 1996).

Ein weiteres Kapitel, in dem zwar bescheidene, aber doch sichtbare Fortschritte zu verzeichnen sind, bezieht sich auf die Berichterstattung zu Umwelt- und Sozialfragen. Aus einer Studie der UNEP über 100 "Pionierunternehmen » aus dem Jahr 1994 geht hervor, dass bei zwei Dritteln der Firmen die Berichte von «grünen Hochglanzprospekten » bis zu Jahresberichten mit mehr Text als Zahlen reichten. Nur 5 Prozent enthielten signifikante Leistungsdaten, während kein einziger als «Berichterstattung über nachhaltige Entwicklung» bezeichnet werden konnte. ${ }^{21}$ Unabhängig davon, wie die Unternehmen ihre Berichte bezeichnen und wie oft die nachhaltige Entwicklung im Text aufscheint, wird in diesem Bereich bislang sehr wenig geleistet (UNEP, 1994: 67). In einer daran anknüpfenden Studie von 1997, die sich ebenfalls auf 100 Unternehmen bezieht, werden bei den meisten untersuchten Firmen wesentliche Fortschrittsbereiche, die nützliches Datenmaterial hergeben, festgestellt (Sustainability and the UNEP, 1997). Allerdings gibt es kaum Beweise für echte Bemühungen, anhand von Nachhaltigkeits-Indikatoren Fortschritte voranzutreiben und nachzuzeichnen, und nur ein einziges Unternehmen schaffte es in die oberste Kategorie der Berichterstattungs-Standards.

Wenn die Umwelt- und Sozialberichterstattung ihren Rückstand wettmacht, dann nur auf sehr selektive Weise. Wie Zadek beobachtet, haben nur wenige Unternehmen - Body Shop und Traidcraft im Vereinigten Königreich, Ben \& Jerry in den Vereinigten Staaten - systematischere, umfassende, exakte und extern geprüfte Methoden zur Untersuchung, Bekanntgabe und Verbesserung der sozialen Leistungen der Unternehmen angenommen (zitiert in Nelson, 1996: 86). Initiativen wie die oben erwähnte GRI verfolgen das Ziel, die Berichterstattung zur Nachhaltigkeit vergleichbarer, genauer und verlässlicher zu gestalten, aber alle diese Bemühungen stecken erst in den Kinderschuhen. Ende 2000 war von nur 26 Unternehmen bekannt, dass sie mit den GRI-Leitlinien arbeiten.

21. Die Berichterstattung über die nachhaltige Entwicklung beruht auf dem extensiven Einsatz quantitativer Methoden (wie Lebenszyklusanalysen und Mengenbilanzen) sowie festen Verbindungen zur industrieübergreifenden und nationalen Berichterstattung über die nachhaltige Entwicklung, gemessen an vorher festgelegten Zielvorgaben (UNEP, 1994: 8). 
In etlichen Entwicklungsländern gibt es kaum Anreize oder Druck auf die Firmen für die Einführung der ökologischen und sozialen Unternehmensberichterstattung (CESR). Gemäss einer Studie verlangen solche Berichte Kosten, Sachkenntnisse und Zeit: In Entwicklungsländern könnten viele Unternehmen nur durch zwingend durchgesetzte Regelungen überhaupt veranlasst werden, Berichte zu erstellen. Heute fehlen solche Regelungen, was zusammen mit weiteren Faktoren zur Annahme berechtigt, dass die CESR in den Entwicklungsländern zumindest in absehbarer Zukunft unattraktiv bleiben dürfte (Shiraz, 1998).

Dass die Reformen erst in der Anfangsphase stecken, zeigt sich auch in Bezug auf die Zertifizierung. ISO 14001 und die Zertifizierungssysteme des Waldverwaltungsrats (FSC) stellen die beiden wichtigsten Initiativen dar. Ende 1999 waren nach diesem Schema weltweit 14'106 Zertifikate vergeben worden. Allerdings nimmt sich diese Zahl im Vergleich zur Zahl der Unternehmen und Produktionsstandorte, die potenziell an solchen Schemata beteiligt werden könnten, äusserst unbedeutend aus. Nur für die TNK-Tochtergesellschaften wurde die Zahl Ende der 90er Jahre auf 690'000 geschätzt (UNCTAD, 2000). Die Anzahl der für das Umweltmanagement vergebenen ISO-Zertifikate steigt zwar jährlich an, erreichte aber 1999 erst 6’219 - eine bescheidene Leistung gegenüber den ungefähr 72'000 Zertifikaten der ISO 9000-Serie, die 1999 für Qualitätsmanagement-Systeme verliehen wurden (ISO, 2000).

Der 1996 veröffentlichte ausführliche Bericht der IIED über die globale Zellstoff- und Papierindustrie hielt fest, dass zwar knapp 6 Millionen Hektar Wald zertifiziert wurden, diese aber nur 0,5 Prozent des globalen Handels ausmachten (IIED, 1996: 62). Anfang 1999 erreichten die von FSC-akkreditierten Stellen zertifizierten Flächen 15 Millionen Hektar (ein Viertel davon in Entwicklungsländern), doch diese Zahl entspricht immer noch weniger als 1 Prozent der weltweiten Waldbestände ausserhalb der Schutzgebiete. 22 Selbst in Costa Rica, wo die Holzindustrie die Förderung der nachhaltigen Forstwirtschaft mittels der Zertifizierung grundsätzlich unterstützte, wurden nur 25'000 Hektar, die zusammen von sieben Unternehmen bewirtschaftet werden, zertifiziert (FSC, 1999). Das entspricht 5 Prozent der ungefähr 500'000 Hektar Wald ausserhalb der Schutzgebiete. ${ }^{23}$

\section{$\square$ Rhetorik versus Realität}

Äusserungen von Unternehmen zur sozialen und ökologischen Verantwortung vermitteln oft den Eindruck, dass inhaltsreiche Innovationen und Veränderungen in beeindruckendem Tempo vorangetrieben worden seien. Rhetorik und Realität klaffen jedoch weit auseinander. Die Leistungen der Geschäftswelt werden in solchen Behauptungen oft stark übertrieben. Forschungsarbeiten in Lateinamerika hatten in zwei Fällen, die in der Fachliteratur zur Unternehmensverantwortung häufig als «Erfolgsgeschichten» gelobt wurden, nachgebohrt: bei der Bio-Prospektionsarbeit des US-Pharmariesen Merck \& Co. in Costa Rica und beim Brasiliengeschäft des Zellstoff- und Papierkonzerns Aracruz Cel-

22. Auf der Basis von Daten der FSC (1999) und Schätzungen zu Wäldern und Schutzgebieten 1996 in: 1999 World Development Indicators (Weltbank, 1999).

23. Auf der Basis von Schätzungen zu Wäldern und Schutzgebieten 1996 in : 1999 World Development Indicators (Weltbank, 1999). 
lulose ${ }^{24}$, mit folgendem Ergebnis: überzogene Behauptungen und Erwartungen (vor allem im Fall von Merck \& Co. (Rodríguez und Camacho, 1999) oder Beispiele für ökologische und soziale Unverantwortlichkeit, vor allem bei Aracruz (Carrere, 1999).

Unabhängige Forschungs- und Kontrollarbeiten in Zentralamerika enthüllten in jüngster Vergangenheit weitere Beispiele von Übertreibungen und Doppelmoral in der Chemiebranche und in der Forstwirtschaft - Industrien, die am häufigsten mit Umweltmanagement-Initiativen zu tun haben. Bei der Bewertung eines bekannten Projekts der internationalen Pestizidindustrie in Guatemala ${ }^{25}$ stellte die Internationale Gewerkschaft der Arbeitnehmer in der Nahrungsmittelbranche und Landwirtschaft (IUL) fest, dass ausgewählte Indikatoren der ProjektPerformance zwar beeindruckend aussahen, die Konzeption und die Umsetzung des Projekts aber gravierende Mängel aufwiesen. Als Pluspunkt ist zu nennen, dass 300'000 Landwirte, Hausfrauen, Studenten und andere Personen zwischen 1991 und 1994 im Einsatz von Schädlingsbekämpfungsmitteln geschult wurden. Allerdings liessen die Ausbildungsmethoden zu wünschen übrig. Die Ausbildungskurse müssten eingehender sein und länger dauern, geeignete Technologien (z.B. «Integrated Pest Management») fehlten, und auf Partizipation beruhende Ausbildungsmethoden wurden ebenfalls vermisst. Überdies wurden die Lohnarbeiter in der Landwirtschaft - also das Gros der Pestizidbenutzer - nicht am Projekt beteiligt, was die Aussagen der Pestizidindustrie, die Produktbetreuung ${ }^{26}$ auf die gesamte Lieferanten-Verwender-Kette ausweiten zu wollen, entkräftete. Da sich die Ausbildung hauptsächlich auf die Landwirte, die Kunden der Pestizidkonzerne sind, ausrichtete und da sie alternative Schädlingsbekämpfungsmethoden ausser Acht liess, sieht sich die Industrie der Anklage ausgesetzt, es handle sich bei diesem Projekt in Wirklichkeit um eine Marketingstrategie (Hurst, 1999). Die durch solche Erhebungen aufgedeckten Probleme unterstreichen die Bedeutung einer unabhängigen Evaluierung und die Notwendigkeit von freiwilligen Initiativen der Unternehmen mit integrierter Überprüfung durch Dritte.

Die zentralamerikanische Forstwirtschaft signalisiert eine gewisse Unterstützung für den Grundsatz der unabhängigen Überprüfung. Allerdings erwachten Bedenken am eigentlichen Überprüfungsprozess. Einmal abgesehen von der heftigen Kritik bestimmter Umweltschützer, wonach sogar unter dem Label «nachhaltige Holzverarbeitung» noch gravierende Umweltschäden angerichtet werden könnten (Colchester, 1990; World Rainforest Movement, 1999) stellten sich noch weitere Probleme: Eine Studie zu einem zertifizierten TeakplantagenUnternehmen in Costa Rica zeigte beispielsweise, dass bestimmte FSCGrundsätze und Kriterien missachtet wurden. So sollen beispielsweise hochtoxi-

24. Siehe Silvia Rodríguez und Mara Antonieta Camacho, «Bioprospecting in Costa Rica: Facing New Dimensions of Social and Environmental Responsibility» (1999); und Ricardo Carrere, «The Environmental and Social Effects of Corporate Environmentalism in the Brazilian Market Pulp Industrie $»(1999)$.

25. Die internationale Pestizidindustrie hat unter dem Druck der Ereignisse und Nachwirkungen des Desasters von Bhopal (Indien) im Jahr 1984 in Guatemala, Kenia und Thailand verschiedene bedeutende Initiativen im Rahmen «Responsible Care Program» und «Safe Use Projects » ergriffen.

26. Produktebetreuung (Product Stewardship) verweist auf die Pflicht der Unternehmen, für Abfälle und Umweltschäden, die ein Produkt verursacht, während des gesamten Lebenszyklus - d.h. von der Gewinnung oder Ernte des Rohstoffs über die Fertigung und Vermarktung der Produkte bis zur Entsorgung und Wiederverwendung die Haftung zu übernehmen (Welford and Jones, 1996: 252). 
sche, in vielen Ländern bereits seit Jahren verbotene Pestizide weiterhin unter gefährlichen Voraussetzungen von Arbeitnehmern benutzt werden, die dafür weder entsprechend geschult noch mit der erforderlichen Schutzkleidung ausgestattet wurden. Ausserdem stellt die Studie fest, dass einige renommierte internationale Umweltschutz-NRO falsche Äusserungen zu den Managementpraktiken und zur ökologischen und ökonomischen Unternehmensbilanz unterstützten (Romeijn, 1999). Gemäss der Studie sind grosse Fragezeichen hinter die Autonomie der Kontrollverantwortlichen, die wissenschaftliche Genauigkeit ihrer Methoden und den Inhalt ihrer Referenzwerte und Ziele zu setzen.

Eine weitere wesentliche Kritik an bestimmten Umweltzertifizierungsformen betrifft die Tatsache, dass das Umweltmanagement und nicht die Umweltauswirkung bewertet wird:27 «Gibt es in Ihrem Unternehmen eine Umweltpolitik?» wird gefragt, und nicht «Inwieweit hat Ihr Unternehmen die Emissionen oder den Energieverbrauch reduziert?». Das Verhältnis zwischen verbessertem Umweltmanagement und Auswirkungen liegt nicht unbedingt auf der Hand; es kann sogar - wie eine Studie zu TNK des Nordens mit Produktionsanlagen in den Vereinigten Staaten betonte - erstaunlich locker sein (Levy, 1995: 57). Vor allem grössere Unternehmen zeichnen sich oft durch starke Worte und schwache Taten aus. 28

In sozialen Aspekten sprechen die Unternehmen selbst bei minimalen Veränderungen von pro-aktiven Massnahmen und von einer wesentlichen Verbesserung der Arbeitsbedingungen. Die «Clean Clothes Campaign» z.B. äussert sich sehr kritisch zu den Angaben von Nike und Reebok, wonach die Löhne der Arbeiter in der Sportschuhbranche in Indonesien 1998-1999 um 40 Prozent erhöht worden seien: Aus dem Zusammenhang gerissen - und das sei der Fall gewesen handle es sich um eine beeindruckende Zunahme; das Bild ändere sich aber grundlegend, wenn man die Zunahme mit den Härten vergleiche, die auf die 70\%-Inflationsrate in den Jahren 1997-1998 zurückgingen, mit der massiven Währungsabwertung und mit den Profiten, die das Konzernen wie Nike und Reebok bescherte. Obwohl die Zunahme deutlich über der Anhebung der staatlichen Mindestlöhne von 15\% liege, zahlten Nike und Reebok immer noch keine Löhne, mit denen sich der Lebensunterhalt bestreiten liesse (Clean Clothes Campaign, 1999).

Am stärksten übertrieben wird wahrscheinlich nicht in spezifischen Fragen des Umwelt- oder Sozialschutzes, sondern mit der Behauptung, dass die Unternehmen auf die «nachhaltige Entwicklung» hin arbeiteten. Etliche Unternehmen, Firmenstiftungen und Geschäftsverbände vergeben das Label «nachhaltige Entwicklung » sehr freigiebig für Initiativen oder Tätigkeiten, die in der Praxis auf recht unerhebliche Massnahmen zur Verbesserung der Umweltmanagementsysteme oder der Ökoeffizienz hinauslaufen. Der WBCSD hat - trotz seines Titels - bis vor kurzem seine ganze Energie in die Förderung der Ökoeffizienz gesteckt.

27. Diese Kritik richtet sich insbesondere gegen ISO 14001 (siehe Krut und Gleckman, 1998); sie wird allgemein in einigen Beiträgen der Fachliteratur zur sozialen Unternehmensverantwortung aufgegriffen (siehe Hopkins, 1997).

28. Eine Erklärung (Levy, 1997: 60) liegt womöglich darin, dass grössere Unternehmen mehr Widerstandskraft gegen die Einführung kostspieliger Investitionen in die Umwelt oder auch mehr bürokratische Trägheit haben. 
Ausserdem konzentrieren sich zahlreiche Unternehmen einseitig auf einen bestimmten Punkt der Unternehmensverantwortung, z.B. auf den Umweltschutz, und ignorieren Aspekte wie Arbeitsbedingungen und Rechte der autochthonen Bevölkerung. Verschiedene internationale Gewerkschaften befürchten, dass Instrumente wie die Umweltzertifizierung die Aktivitäten von Unternehmen, welche nach wie vor grundlegende Rechte mit Füssen treten, legitimieren könnten. Die Internationale Gewerkschaft der Bau- und Holzarbeiter (IFBWW) plädierte dafür, zusätzliche Sozialkriterien aus den IAO-Kernnormen in die Waldzertifizierung einzuführen (Development and Cooperation, 1999: 31). Die Internationale Gewerkschaft der Arbeitnehmer in der Nahrungsmittelbranche und Landwirtschaft (IUL) übt scharfe Kritik an Bananenkonzernen wie Chiquita Brands, welche das ECO-OK Label übernommen haben (danach ist ein Unternehmen verpflichtet, den Einsatz toxischer Pestizide einzuschränken). Nach Aussagen von Gewerkschaftsorganisationen und -funktionären führt Chiquita jedoch weiterhin umweltschädliche Praktiken durch; schlimmer noch, das Unternehmen beschneidet in Ländern wie Costa Rica die Grundrechte betreffend die Vereinigungsfreiheit der Arbeitnehmer (persönliches Gespräch mit einem SITRAP-Beamten ;29 IUL, 1998).

Das Konzept nachhaltige Entwicklung umfasst mehr als nur den Umweltschutz. Die Kernelemente des von der Weltkommission für Umwelt und Entwicklung propagierten Konzepts beinhalten auch die Befriedigung der menschlichen Bedürfnisse und Gerechtigkeit innerhalb und unter den Generationen (WCED, 1987). Wie sich diese Ziele erreichen lassen, steht selbstverständlich noch zur Diskussion. Eine Strategie mit dem Label nachhaltige Entwicklung müsste jedoch vielfältige Dimensionen umfassen. So hiess es beispielsweise, dass Unternehmen, die den Beitrag an die nachhaltige Entwicklung ernst nehmen, in sechs Bereichen kontinuierliche Fortschritte nachweisen müssten (Welford, 1997). Dabei handelt es sich um Umweltleistung, das «Empowerment» (Befähigung zur Eigenverantwortung) von Beschäftigten (Arbeitnehmerrechte und -beteiligung), Wirtschaftsleistung (nachhaltige Rentabilität, Schaffung von Arbeitsplätzen, faire Löhne), Ethik (Verhaltenskodizes, Transparenz, Rechenschaftspflicht der Anspruchsgruppen), Gerechtigkeit (fairer Handel und faire Behandlung der Anspruchsgruppen) und Erziehung (Verbreitung von Information, Beteiligung an Kampagnen). Nur sehr wenige Unternehmen haben sich bemüht, eine solch umfassende Strategie zu verabschieden.

Abgesehen von der Tatsache, dass entscheidende Dimensionen der nachhaltigen Entwicklung aussen vor bleiben, erhalten die Modelle für Wachstum, Verbrauch und Nord-Süd-Beziehungen, die der «unnachhaltigen» Entwicklung zugrunde liegen, durch bestimmte Aspekte der betrieblichen Umweltpolitik sogar noch Auftrieb. So wird beispielsweise vom Eco-Labelling befürchtet, dass es sich als nicht-tarifäre Handelsschranke erweisen und den Entwicklungsländern schaden könnte (Markandya, 1997). Laut Dawkins (1995: 5-6) könnte das Eco-Labelling aktuelle globale Trends, wonach der Anteil der Entwicklungsländer an den Weltmärkten schrumpft und wonach in allen Ländern der Anteil der kleinen Unternehmen an nationalen und internationalen Märkten zurückgeht, verschärfen, wenn die Eco-Labelling-Systeme nicht mit energischen Förderungspoliti- 
ken zur Erleichterung der Beteiligung kleiner Unternehmen und Exporteure aus Entwicklungsländern einhergehen.

Eine Studie des internationalen Gartenbausektors (UNCTAD und SGS, 1998) lässt ein Potenzial für zusätzliche umweltverträgliche Produktionsformen ersehen. Dafür sind allerdings erhebliche Investitionen, Zugang zur Information und Managementerfahrungen erforderlich, was für viele Kleinproduzenten ausser Reichweite liegt. Im Endeffekt richten sich Supermärkte und Importeure auf immer weniger, grössere, besser organisierte und technisch kompetentere Züchter, Verarbeiter und Exporteure aus. In diesem Prozess werden kleinere Produzenten tendenziell vom Markt gedrängt (UNCTAD und SGS, 1998: 7), selbst wenn einige Marktnischen - z.B. für Bio-Obst und -Gemüse - von kleineren Landwirten beliefert werden.

Ähnlich herrscht in Bezug auf die soziale Unternehmensverantwortung die Sorge, dass viele Firmen in Entwicklungsländern mit der Erfüllung der neuen, von ihren Abnehmern - transnationalen Konzernen oder grossen Einzelhandelsunternehmen - vorgegebenen Standards überfordert sein dürften. Unter solchen Umständen muss das Konzept der Unternehmensverantwortung nicht nur die Anhebung der Standards, sondern auch die verbesserte Befähigung des Zulieferers zu deren Einhaltung einschliessen. Ausserdem darf die Einhaltung der Standards keine anderen «Fehlentwicklungen» hervorrufen - z.B. wenn durch den Kampf gegen die Kinderarbeit die Familien in noch stärkere Armut sinken oder die Kinder selbst in noch missbräuchlichere Arbeitsformen getrieben werden.

Initiativen auf dem Gebiet der Umweltpolitik der Unternehmen motivieren Verbraucher nur in seltenen Fällen, sich auf ein unterschiedliches Konsumverhalten umzustellen, das die Umweltzerstörung signifikant eindämmen könnte. Die oben erwähnte Fallstudie der IUL zeigte, dass beispielsweise bei der Schulung für den Chemikalieneinsatz der Schwerpunkt auf einer schonenderen Verwendung der herkömmlichen Pestizide, nicht auf der Förderung alternativer Schädlingsbekämpfungsmethoden, lag. Allgemeiner gesagt haben die Verbraucher oft nur die Wahl zwischen ähnlichen Produkten, die sich in ihren Auswirkungen auf die Umwelt nur geringfügig unterscheiden; sie werden nicht angespornt, ihren Lebensstil und ihre Konsumgewohnheiten zu überdenken (West, 1995: 19). Ähnliches gilt für Erdölkonzerne, die sich um einen Dialog mit verschiedensten Anspruchsgruppen bemühen, um bestimmte Initiativen zu erörtern: Diskutiert wird in der Regel, wie ein besonderes Projekt umgesetzt werden sollten, nicht ob es grundsätzlich durchzuführen sei (Rowell, 1999).

\section{$\square$ Vor lauter Bäumen den Wald nicht sehen}

Wer die Aufmerksamkeit auf die spezifischen Initiativen und Innovationen konzentriert, die einzelne Unternehmen in Sachen Umwelt- und Sozialverantwortung eingeführt haben, verliert den breiteren Zusammenhang - sprich die Investitionsmodelle und die Produktion, die Wirtschaftsliberalisierung und deren ökologische und soziale Konsequenzen - leicht aus den Augen.

Selbst wenn die Vorstandsvorsitzenden von Unternehmen, die an der Speerspitze der Verantwortungsbewegung stehen, verlautbaren, dass sie sich nicht nur für das einzige Ziel der Rentabilität, sondern zunehmend für ein dreifaches Ziel engagierten - auch für Umwelt und Soziales - fliessen die Investitionen doch 
grösstenteils in Tätigkeiten des «Business-as-usual» (Welford, 1997). In einem jüngsten Interview der CNN verglich der Vorsitzende von Shell sein Unternehmen mit einem dreibeinigen Hocker : Alle drei Beine - Symbole für das finanzielle, ökologische und soziale Ziel - seien für die Stabilität wichtig. Das Problem bei diesem Vergleich ist, dass die drei Beine bei weitem nicht gleich lang sind. Der Umfang der für Umwelt- und Sozialanliegen aufgewendeten Konzernressourcen verblasst gegenüber den Beträgen, dank denen aus konventionellen Geschäftssparten Gewinne erwirtschaftet werden sollen. Ein Blick auf das Investitions-Portfolio 1999 von BP Amoco verdeutlicht das Argument. Der Konzern stockte zwar die Beteiligung im Sonnenenergiebereich über den Kauf von Solartex (45 Millionen \$) auf (Bruno, 1999), aber das Gros der Investitionen wurde in die regelmässige Expansion von nicht-erneuerbaren Ressourcen gepumpt (z.B. mit dem Übernahmeangebot des Erdölkonzerns ARCO für rund 31 Milliarden \$) (BP Amoco, 1999). Gemäss dem Greenpeace-Medienzentrum wurden pro 10’000 \$, die BP Amoco 1998 für die Erdölprospektion und -entwicklung ausgab, 16 \$ für die Sonnenenergie aufgewendet (Media Center, 1999). Der Vergleich der drei Unternehmensziele mit dem dreibeinigen Hocker hinkt also ziemlich stark.

Verschiedene strukturelle Aspekte, die sich auf die Organisation der Produktion beziehen, grenzen die Unternehmensverantwortung ein. Oft wird argumentiert, eine grundlegende Schranke der Umwelt- und Sozialpolitik von Unternehmen ergebe sich aus der Logik der kapitalistischen Produktion, sprich dem Streben nach Rentabilität, das Unternehmen unter Kostensenkungsdruck setze und sie zwinge, zu externalisieren und sich nach Standorten mit schwachen Arbeitsund Umweltvorschriften umzusehen. Im härteren Wettbewerb, den die Globalisierung und Liberalisierung mit sich brachten, hat sich dieser Druck offenbar verschärft. Fusionen und Übernahmen, Personalabbau, Feminisierung und Informalisierung der Beschäftigung sowie die Köderwirkung von weitgehend deregulierten Oasen (z.B. der Ausfuhrfreizonen) bewirken, dass etliche Unternehmen ihre Kernbelegschaft kürzen und die Produktion an Standorte und Systeme mit niedrigeren Sozial- und Umweltauflagen und einer schwachen bzw. fehlenden gewerkschaftlichen Organisation verlegen.

Besonders akut zeigt sich das Spannungsfeld zwischen Profit und Verantwortung in den Frühphasen der Unternehmenstätigkeit, wenn die Firmen durch eine möglichst weitgehende Kostenexternalisierung rasche Erträge aus den umfassenden Investitionen anstreben. Dieses Problem wird in einer Untersuchung zur brasilianischen Zellstoffindustrie aufgedeckt (Carrere, 1999), aus der auch hervorgeht, dass Machtstrukturen den Prozess verstärken können. Die grossen brasilianischen Zellstoffirmen warfen nicht nur ihr politisches und wirtschaftliches Gewicht in die Waagschale, um von der Regierung Subventionen zu erhalten, sondern hatten die Staatsmacht sogar auf ihrer Seite, als die Externalitäten lokal auf Widerstand stiessen. Daneben verweist die Analyse zur ökologischen und sozialen Unternehmensverantwortung in diesem Bereich auf ein weiteres strukturelles Problem: die Grösse. Selbst Unternehmen, die sich für Umweltschutz und nachhaltige Entwicklung engagieren, können ihre Ziele nicht erreichen, wenn wegen des schieren Ausmasses ihres Geschäftsbetriebs entsprechende Umweltauswirkungen unvermeidbar sind (Carrere, 1999). Besteht also nur die Wahl zwischen mehr oder weniger umweltzerstörenden Unternehmen, oder müsste auch die Möglichkeit existieren, ein Wirtschaftssystem, das auf kleine- 
ren, besser auf die lokale Kultur und die Umwelt abgestimmten Unternehmen beruht, zu fördern? (Carrere, 1999).

Den breiteren Zusammenhang im Auge zu behalten bedeutet auch, sich mit der Struktur der nationalen, regionalen und sektoriellen Investitionstätigkeit auseinander zu setzen. Obwohl heute immer mehr Firmen Massnahmen zur Verbesserung der Umweltmanagementsysteme treffen und obwohl Einrichtungen entstehen, die diese Entwicklung vorantreiben, weist das Wirtschaftssystem als Ganzes nach wie vor Fehlentwicklungen auf, wie sich in Mexiko zeigte (Barkin, 1999). Die Investitionsstrategien führen zur Expansion von umweltverschmutzenden Industrien. Die Tendenzen in der Industrieansiedlung legen ausserdem den Schluss nahe, dass Firmen gezielt in Landesteilen mit schwacher Planung und Regulierung errichtet bzw. verlagert werden. Wie im Zusammenhang mit Indien festgestellt wurde, lässt sich der Deregulierungswettbewerb, durch den Investitionen angelockt werden sollen, nicht nur zwischen den Ländern, sondern auch unter den Regionen oder Bundessaaten innerhalb eines Landes feststellen. (Jha, 1999).

Auch institutionelle Strukturen, vor allem in der makroökonomischen Politik, schränken bisweilen die Umwelt- und Sozialverantwortung der Unternehmen ein. Dies lässt sich z.B. in Zentralamerika beobachten (Pratt und Fintel, 1999): Firmen sind schwer für Umweltverbesserungen zu gewinnen, wenn zum Beispiel der Finanzdienstleistungssektor hohe Zinsen und kurze Kreditfristen diktiert. Solche Voraussetzungen halten Unternehmen möglicherweise davon ab, mit einem langfristigen Planungshorizont, den das Umweltmanagement oft erfordern würde, zu arbeiten. Weitere Massnahmen in diesem Sektor - z.B. Empfehlungen für den Einsatz bestimmter Techniklösungen - können Landwirte dazu verleiten, veraltete und umweltschädliche Technologien einzusetzen. Auch der Fiskus bestraft die Importe und Einführung von sauberen Technologien und schätzt die Verwendung der natürlichen Ressoucen unter ihrem Wert ein (Pratt und Fintel, 1999).

Die Fortschrittskurve in der Unternehmensverantwortung verläuft nicht linear, sondern mit Hochs und Tiefs, und bricht zeitweise völlig ab. Das ist vor allem in Zeiten der wirtschaftlichen Rezession der Fall, wenn Firmen auf verschiedenste Weise - mit möglichen negativen ökologischen und sozialen Konsequenzen - die Kosten zu senken versuchen. Vielleicht äussern sich darin auch Ânderungen im sozialen Kräftegleichgewicht, wenn soziale und politische Kreise, die der Deregulierung das Wort reden oder sich gegen die Einführung einer Regulierung sperren, erstarken, bzw. jene, die eine Regulierung in unterschiedlicher Form befürworten, an Einfluss verlieren. Die Rolle der globalen Klimakoalition, die den Kyoto-Prozess verwässern, ja gar aus der Bahn werfen wollte, ist ein Schulbeispiel dafür.

Diese breiteren Trends zusammen mit der Entwicklung der kapitalistischen Produktion und der Wirtschaftsliberalisierung wecken gravierende Besorgnis über den Prozess der Umwelt- und Sozialverantwortung der Unternehmen. Allerdings zeigt sich auch, dass bestimmte Abläufe und Kräfte der Globalisierung die Unternehmensverantwortung sogar stärken. 


\section{FÖRDERUNG DER SOZIALEN UND ÖKOLOGISCHEN VERANTWORTUNG DER UNTERNEHMEN}

Der begrenzte Umfang des Wandels erklärt sich teilweise daraus, dass es sich bei der sozialen Unternehmensverantwortung um eine sehr junge Bewegung handelt, die im Grunde erst in den 90er Jahren in Schwung kam. Daher ist zu untersuchen, ob Kräfte oder günstige Voraussetzungen existieren, die zu einer Verstärkung der Initiativen für die Unternehmensverantwortung führen könnten. In diesem Sinn ist Optimismus berechtigt, da einige recht mächtige Kräfte die Unternehmensveranwortung vorantreiben. Drei davon besitzen offenbar eine besondere Bedeutung.

Erstens macht es für einige Unternehmen ökonomisch Sinn, ihre sozialen und ökologischen Leistungen und ihr Image $\mathrm{zu}$ verbessern, um auf den neuen Märkten für «ethische» oder grüne Produkte und Dienstleistungen Fuss zu fassen und sich einen Vorsprung gegenüber den Mitbewerbern $\mathrm{zu}$ sichern. Zweitens kennzeichnete sich die Globalisierung durch die Ausweitung der globalen Angebotsketten. Die TNK-Sitze haben in einigen Sektoren durchaus ein Interesse daran, sicherzustellen, dass ihre Tochtergesellschaften und Zulieferer sich an die minimalen Arbeits- und Umweltnormen halten, um eine Firma oder ein Produkt nicht bei den Verbrauchern in Verruf zu bringen und um den "Shareholder value» und die Marktanteile nicht zu gefährden. Aus diesem Grund werden einige TNK-Sitze dafür sorgen, dass ihre Tochtergesellschaften und Untervertragsnehmer die Verhaltenskodizes erfüllen oder eine Umweltzertifizierung einführen. Drittens - und dabei handelt es sich um den wohl wichtigsten Faktor - ist eine recht einflussreiche globale Sozialbewegung entstanden, die von den Unternehmen vermehrt Rechenschaft fordert. Besonders in den reicheren Industrieländern besitzt diese Bewegung grosses Gewicht; sie rückt einige TNK immer wieder ins Rampenlicht und zwingt sie, positive Lösungen zu finden.

Solche Triebkräfte mögen zwar Unternehmen zu einem verantwortungsvolleren Umgang mit ökologischen und sozialen Problemen motivieren, aber die Veränderungen werden höchstwahrscheinlich Stückwerk bleiben - unregelmässig auf Unternehmen, Länder und Sektoren verstreut und hinsichtlich der nachhaltigen Entwicklung mit Widersprüchen befrachtet. Diese letztlich minimalistische und ungleichmässige Agenda erklärt sich nicht nur aus dem sehr jungen Veränderungsprozess, sondern geht auch darauf zurück, wie die Unternehmen auf ökonomische, politische und strukturelle Triebkräfte des Wandels reagieren: Die Reaktionen beschränken sich oft auf die Imagepflege, Öffentlichkeitsarbeit und oberflächliche Anpassungen im Management, während die Auswirkungen der Unternehmensaktivitäten auf Gesellschaft und Umwelt kaum tangiert werden.

Angesichts der heute relativ schwachen Motoren der sozialen und ökologischen Unternehmensverantwortung stellt sich die Frage, wie die Trends der Bewegung gefestigt und vertieft werden können, damit die Geschäftswelt einen relevanteren Beitrag an die nachhaltige Entwicklung leisten kann. Die vorherrschenden institutionellen Ansätze, die derzeit hoch im Kurs stehen, konzentrieren sich auf die Förderung von «freiwilligen Initiativen» und «Partnerschaften».

Freiwillige Initiativen umfassen eine breite Palette von Initiativen, die über die geltenden Gesetze und Gesetzgebungen in den Bereichen Umwelt- und sozialer 
Schutz hinausgehen. Oft gelten freiwillige Initiativen als wirksame Alternative zu zwingenden Gesetzen, zumal sie häufig ehrgeizigere Ziele verfolgen, zur Senkung der Verwaltungs- und Vollzugskosten beitragen können und sich rascher umsetzen lassen als Gesetze (UNEP, 2000). Solche Massnahmen bieten aber neben erheblichen Vorteilen auch gravierende Nachteile.

Die Schwäche vieler oben beschriebener Formen von freiwilligen Initiativen besteht darin, dass sie ohne Rücksicht auf die Grundsätze der Transparenz, ohne unabhängige Überprüfung und ohne Beteiligung der Arbeitnehmer und der Gemeinschaften konzipiert werden. Ausserdem werden bestimmte Initiativen wie Verhaltenskodizes und Zertifizierungssysteme in der Regel von Akteuren des Nordens - Regierungen, NRO oder Wirtschaftskreisen - erarbeitet, während die südlichen Regierungen und NRO in der Beschlussfassung, die sie direkt betrifft, an den Rand gedrängt werden.

Das offensichtlichste Problem besteht darin, dass nur wenige Unternehmen freiwillige Initiativen verabschieden dürften. Anders als bei Gesetzen fehlt in der Regel ein Mechanismus, der säumige Unternehmen zwingt, die strengeren Normen zu erfüllen. Für den Erfolg der freiwilligen Initiativen ist oft ein bestimmter institutioneller Rahmen erforderlich - zum Beispiel grundlegende Gesetze zur Informationsbekanntgabe und -freiheit, «Watch-dog»-Institutionen und starke Bewegungen der Zivilgesellschaft. In zahlreichen Ländern sind solche Voraussetzungen nur ansatzweise oder gar nicht vorhanden.

In einer Bewertung der OECD zu bestimmten Formen von freiwilligen Initiativen konnte eine ökologische Effizienz nur begrenzt nachgewiesen werden, obwohl sie «weichere» Auswirkungen - Informationsverbreitung und Sensibilisierung - zeitigen (OECD, 1999b). Der Bericht erwähnt das Problem der Trittbrettfahrer und warnt vor der Gefahr der «Entwendung der Regelungskompetenz», wonach die Industrie sich mit freiwilligen Initiativen Einfluss über die staatliche Politik verschafft.

Partnerschaften zwischen dem Geschäftssektor und NRO oder multilateralen Organisationen rechtfertigen sich in der Regel dadurch, dass die zunehmend globalisierte und integrierte Welt neue Formen der Regierungsführung voraussetzt - Kooperation statt Konfrontation aller Beteiligter. Den Regierungen fehlt jedoch die Gestaltungsmacht, um die aktuelle Wirtschaftsentwicklung mitzubestimmen; ausserdem werden ihre Befugnisse in vieler Hinsicht beschnitten. Vor diesem Hintergrund, so die Argumente, müssten der Privatsektor, die Zivilgesellschaft, multilaterale Institutionen und Regierungen in öffentlich-privaten Partnerschaften zusammenarbeiten, um die komplexen und miteinander verknüpften Themen, denen nur mit kooperativen, integrierten und umfassenden Lösungen innerhalb und unter den Nationen beizukommen ist, gemeinsam zu bewältigen (Nelson, 1996: 13).

Dieser anscheinend pragmatische, konstruktive und kooperative Ansatz ist bestechend. Viele Organisationen sind davon derart begeistert, dass sie sich Hals über Kopf und ohne die Konsequenzen kritisch zu überdenken in «Partnerschaften» mit der Geschäftswelt stürzen. Besonders alarmierend sind die unzulänglichen Kriterien, wonach die Vereinten Nationen und andere Organisationen ihre Partner unter den Unternehmen auswählen, die Art und Weise, auf welche die Kritik an der Annäherung zwischen NRO und UN-Organisationen unterdrückt wird, und das Problem der «Entwendung der institutionellen Kom- 
petenz», wenn Unternehmen Einfluss auf Entscheidungsfindungsprozesse des öffentlichen Bereichs ausüben (Utting, 2000b).

Grösste Skepsis weckt bei freiwilligen Initiativen wie bei Partnerschaften die Tatsache, dass sie die Triebkräfte der Unternehmensverantwortung - die staatliche Regulierung, die Tarifverhandlungen und bestimmte Aktionen der Zivilgesellschaft - schwächen könnten. Aus der Geschichte der Umwelt- und Sozialverantwortung der Unternehmen und der grossen aktuellen Reformen der Unternehmenspolitik und -praktiken zeigt sich, dass zumindest einer dieser Faktoren immer massgeblich mitgespielt hat.

Freiwillige Initiativen werden zu oft als von der staatlichen Regulierung unabhängig, ja gar als Alternative dazu gesehen. In Wirklichkeit sind jedoch oft Gesetze und staatliche Sanktionen in verschiedener Form für ihr Entstehen und ihren Erfolg ausschlaggebend. Freiwillige Initiativen, die auf unterschiedliche Weise an Regelungen und unabhängige Kontrolle geknüpft werden, erweisen sich häufig als effizienter (UNEP, 2000).

Fortschritte in der sozialen und ökologischen Verantwortung der Unternehmen sind entscheidend auf die Stärkung der Bewegung für die Rechenschaftspflicht der Unternehmen angewiesen. Diese Bewegung stellt Unternehmen ins Rampenlicht der Öffentlichkeit, enthüllt und verurteilt Missbräuche, bringt die Reputation der Unternehmen in Gefahr und fordert von ihnen bessere sozialund umweltpolitische Leistungen. Mehrere Sektoren des Grosskapitals müssen sich heute diesem Druck beugen, wenn auch einige sich dabei auf bruchstückhafte Änderungen der Unternehmenspolitik und -praxis beschränken.

Solange staatliche und internationale Regelungen und ein besser abgestimmter und koordinierter Druck der Zivilgesellschaft ausbleiben, wird die Förderung der ökologischen und sozialen Verantwortung der Unternehmen bestenfalls lauwarm bleiben. Nach der oben dargelegten Analyse zu den Triebkräften des Wandels ist anzunehmen, dass die Unternehmen weitere Massnahmen bezüglich der sozialen und ökologischen Verantwortung verabschieden werden. In dieser Hinsicht lassen sich Änderungen der Unternehmenspolitik und -praxis - anders als bestimmte Beobachter denken - nicht einfach als PR-Massnahmen oder als Schönfärberei abtun. Trotzdem bilden die fraglichen Initiativen ein sehr minimalistisches und durchwachsenes Programm. Da sie den störungsfreien Ablauf von Produktion und Marketing erleichtern und oft alternative Änderungsprogramme verwässern, dienen sie letztlich möglicherweise eher dem Wirtschaftswachstum und der Stabilität des Kapitalismus als der nachhaltigen Entwicklung.

\section{LITERATURVERZEICHNIS*}

Annan, K. (1999), "A compact for the new century», Address to the World Economic Forum, Davos, 31 January (www.un.org/partners/business/davos.htm).

Barber, J. (1998), « Responsible action or public relations? NGO perspectives on voluntary initiatives», Industry and Environment, Vol. 21, No. 1-2, January-June, pp. 19-22.

Barkin, D. (1999), The Greening of Business in Mexico, Discussion Paper No. 110, UNRISD, Geneva.

Bendell, J. (ed.) (1998), «Business-NGO relations and sustainable development», Greener Management International: The Journal of Corporate Environmental Strategy and Practice, Issue 24, winter.

Bennett, T. (1986), «Introduction: Popular culture and 'the turn to Gramsci' ", in T. Bennett, C. Mercer and J. Woollacott (eds.), Popular Culture and Social Relations, Open University Press, Milton Keynes.

BP Amoco (1999), Shareholder Documents: Listing Particulars, (www.bpamoco.com/investors/arco/ egm.htm). 
Bruno, K. (1999), «Summer greenwash award: BP Amoco's 'Plug in the Sun' program», in Corporate Watch Greenwash Awards,

(www.corpwatch.org/trac/greenwash/bp.html).

BUSCO (1995), Contribution of Corporations to Social Development, Business Association for the World Social Summit, Paris.

Carrere, R. (1999), The Environmental and Social Effects of Corporate Environmentalism in the Brazilian Market Pulp Industry, mimeo, UNRISD, Geneva (proposed chapter in P. Utting (ed.), op.cit.).

Chatterjee, P. and M. Finger (1994), The Earth Brokers: Power, Politics and World Development, Routledge, London.

Clean Clothes Campaign (1999) (www.cleanclothes.org/codes/inilivingwa.htm).

Colchester, M. (1990), «The international tropical timber organization: Kill or cure for the rainforests?», The Ecologist, Vol. 20, No. 5, pp. 166-173.

Corporate Watch (1996) (www.oneworld.org).

CSD (1999), Voluntary initiatives and agreements: Report of the Secretary-General, United Nations Economic and Social Council, E/CN.17/1999/12, 5 April.

Currah, K.R. (1999), Activating the Self-correcting Mechanism of Civil Society, mimeo, World Vision, Milton Keynes.

Dawkins, K. (1995), Ecolabelling: Consumer's Right to Know or Restrictive Business Practice?, mimeo, Institute for Agriculture and Trade Policy, Minneapolis.

Development and Cooperation (1999), «Certification to save the world's forests », D+C, No 2.

Dommen, E. (1999), Pertinence et limites des codes éthiques, mimeo, Geneva.

Evans, P. (1998), «Transnational corporations and Third World states: From the old internationalization to the new », in Kozul-Wright and Rowthorn (eds.), op cit.

FAO (1997), State of the World's Forests, 1997, FAO, Rome.

Flaherty, M. and A. Rappaport (1991), Multinational Corporations and the Environment: A Survey of Global Practices, The Center for Environmental Management, Tufts University, Medford.

Flaherty, M. and A. Rappaport (1999), Corporate Environmentalism: From Rhetoric to Results, mimeo, UNRISD, Geneva (proposed chapter in P. Utting (ed.), op.cit.).

Forcese, C. (1996), Commerce with Conscience? Human Rights and Business Codes of Conduct, International Centre for Human Rights and Democratic Development, Montreal.

Forgacs, D. (1988), An Antonio Gramsci Reader: Selected Writings, 1916-1935, Schocken Books, New York.

Fortune (1999), 1999 Global 5 Hundred, Vol. 140, No. 3, August.

Frankel, C. (1999), "One foot in the future», Tomorrow, Vol. IX, No. 1, January/February, pp. 11-12.

Freeman, R. (1984), Strategic Management: A Stakeholder Approach, Pitman, Boston.

FSC (1999)(www.fscoax.org).

Gallin, D. (1999a), Organized Labour as a Global Social Force, paper presented at IR2 Workshop, Washington, DC, 20 February 1999.

Gallin, D. (1999b), Trade Unions and NGOs in Social Development: A Necessary Partnership, mimeo, UNRISD, Geneva.

Gereffi, G. (1994), «Capitalism, development and global commodity chains », in L. Sklair (ed.), Capitalism and Development, Routledge, London.

Gereffi, G., M. Korzeniewicz and R. Korzeniewicz (1994), «Introduction: Global commodity chains», in Gereffi and Korzeniewicz (eds.), Commodity Chains and Global Capitalism, Greenwood Press, London.

Gonçalves, M.T. et al. (1994), Exploraçao florestal no norte do ES e sul da Bahia: Impactos e alternativas, FASE/IBASE, Rio de Janeiro.

Greer, J. and K. Bruno (1996), Greenwash: The Reality Behind Corporate Environmentalism, Third World Network, Penang.

Hagen, K. (1998), «Issues involving codes of conduct from an ILO perspective», in A.Wild, op.cit.

Hanks, J. (1999), Promoting Corporate Environmental Responsibility: What Role for 'Self-regulatory' and 'Co-regulatory' Policy Instruments?, mimeo, UNRISD, Geneva (proposed chapter in P. Utting (ed.), op.cit.).

Hansen, M. (1999a), Environmental Regulation of Transnational Corporations: Needs and Prospects, mimeo, UNRISD, Geneva (proposed chapter in P. Utting (ed.), op.cit.).

Hansen M. (1999b), Environmental Management in Transnational Corporations in Asia: Does Foreign Ownership Make a Difference? Preliminary Results of a Survey of Environmental Management Practices in 154 TNCs, Occasional Paper, CBS/UNCTAD Cross Border Environmental Management Project, Copenhagen Business school, Copenhagen 
Harverson, P. and R. Corzine (1997), «In defence of international reputations", Financial Times, 31 October, p. 15.

Hawken, P. (1993), A Declaration of Sustainability, September/October, Utne Reader.

Henderson, H. (1996), Building a Win-Win World, Berrett-Koehler Publishers, San Francisco.

Hirst, P. and J. Zeitlin (1991), «Flexible specialisation versus post-Fordism: Theory, evidence and policy implications », Economy and Society, Vol. 20, No.1, February, pp. 1-56.

Hopkins, M. (1997), «Defining indicators to assess socially responsible enterprises», Futures, Vol. 29, No. 7, pp. 581-603.

Hurst, P. (1999), IUF Case Study: The Global Pesticide Industry's «Safe Use and Handling» Training Project in Guatemala, International Union of Food and Agricultural Workers, Geneva.

IFAT (1999), The Business of Fair Trade: Livelihoods, markets and sustainability, conference report, IFAT, Oxford.

IIED (1996), Towards a Sustainable Paper Cycle, IIED/WBCSD, London/Geneva.

ILO, Sectoral Activities Programme (1999), Voluntary initiatives affecting training and education on safety, health and environment in the chemical industries, ILO, Geneva.

ISO (1998), ISO 14000: Meet the Whole Family!, International Organization for Standardization, Geneva.

ISO (1999), The ISO Survey of ISO 9000 and ISO 14000 Certificates. The eighth cycle - 1998, International Organization for Standardization, Geneva.

IUF (1998), «International banana conference explores routes 'towards a sustainable banana economy'», IUF News Bulletin, Nos. 3 and 4, International Union of Food and Agricultural Workers, Geneva.

Jeanrenaud, S. (1998), Can the Leopard Change its Spots? Exploring People-Oriented Conservation within the $W W F$, doctoral thesis, University of East Anglia, Norwich.

Jha, V. (1999), Investment Liberalization and Environmental Protection: Conflicts and Compatibilities in the Case of India, Occasional Paper, CBS/UNCTAD Cross Border Environmental Management Project, Copenhagen Business School, Copenhagen.

Kasperson, R., R.Kates, C. Honenemser and J. Kasperson (1988), Corporate Management of Health and Safety Hazards: A Comparison of Current Practice, Westview, Boulder.

Kolk, A., R. van Tulder and C. Welters (1999), «International codes of conduct and corporate social responsibility: Can transnational corporations regulate themselves?», Transnational Corporations, Vol. 8, No. 1, April, pp.143-180.

Kolodner, E. (1994), Transnational Corporations: Impediments or Catalysts of Social Development?, Occasional Paper No. 5, World Summit for Social Development, UNRISD, Geneva.

Kozul-Wright, R. and B. Rowthorn (1998), «Introduction: Transnational corporations and the global economy ", in Kozul-Wright and Rowthorn (eds.), Transnational Corporations and the Global Economy, Macmillan, London.

Krut, R. (1997), Globalization and Civil Society: NGO Influence in International Decision-making, Discussion Paper No. 83, UNRISD, Geneva.

Krut, R. and H. Gleckman (1998), ISO 14001: A Missed Opportunity for Sustainable Global Industrial Development, Earthscan, London.

Levy, D. (1995), «The Environmental Practices and Performance of Transnational Corporations», Transnational Corporations, Vol. 4, No. 1, April, pp.44-67.

Levy, D. (1997), «Environmental management as political sustainability », Organization \& Environment, Vol. 10, No. 2, June, pp. 126-147

Markandya, A. (1997), «Eco-labelling: An introduction and review», in S. Zarrilli, V. Jha and R. Vossenaar (eds.), Eco-Labelling and International Trade, Macmillan, London.

Media Center (1999), «We laughed! We cried! But mostly we cried !», Press Releases (www.greenpeaceusa.org/media/press_releases/99_4_22text.htm).

Murphy, D. and J. Bendell (1999), Partners in Time? Business, NGOs and Sustainable Development, Discussion Paper No. 109, UNRISD, Geneva.

Nelson, J. (1996), Business as Partners for Development: Creating Wealth for Countries, Companies and Communities, The Prince of Wales Business Forum, London.

NEF and CIIR (1997), Open Trading: Options for Effective Monitoring of Corporate Codes of Conduct, NEF/CIIR, London.

Novartis (1998), Report of the Novartis Foundation for Sustainable Development 1997/1998, Novartis Foundation for Sustainable Development, Basel.

OECD (1999a), Codes of Corporate Conduct: An Inventory, OECD, Paris.

OECD (1999b), Voluntary Approaches for Environmental Policy: An Assessment, OECD, Paris

O'Neill, K. (1999), Internetworking for Social Change: Keeping the Spotlight on Corporate Environmentalism, Discussion Paper No. 111, UNRISD, Geneva. 
Porter, M. and C. van der Linde (1995), «Green and competitive: Ending the stalemate», Harvard Business Review, September-October, pp. 120-134.

Pratt, L. and E. Fintel (1999), Environmental Management as an Indicator of Business Responsibility in Central America, mimeo, UNRISD, Geneva (proposed chapter in P. Utting (ed.), op.cit.).

Richter, J. (forthcoming), The Regulation of the Infant Food Industry (provisional title).

Roddick, A (1998) «Profiting the poor» Developments, Issue 2, Second Quarter, pp. 5-7.

Rodríguez, S. and M.A. Camacho (1999), Bioprospecting in Costa Rica: Facing New Dimensions of Social and Environmental Responsibility, mimeo, UNRISD, Geneva (proposed chapter in P. Utting (ed.), op.cit.).

Romeijn, P. (1999), Green Gold: On Variations of Truth in Plantation Forestry, Treebook 2, Treemail Publishers, Heelsum, the Netherlands.

Rowell, A. (1999), "Greenwash goes legit», Guardian, 21 July, p.5.

Sargent, C. and S. Bass (eds.) (1992), Plantation Politics: Forest Plantations in Development, Earthscan, London.

Schmidheiny, S. (1992), Changing Course: A Global Business Perspective on Development and the Environment, MIT Press, Cambridge, Massachusetts.

Schmidheiny, S., R. Chase and L. DeSimone (1997), Signals of Change: Business Progress towards Sustainable Development, WBCSD, Geneva.

Schmidheiny, S. and F. Zorraquín, with WBCSD (1996), Financing Change: The Financial Community, Eco-Efficiency, and Sustainable Development, MIT Press, Cambridge, Massachusetts.

Schrempp, J. (1997), «Corporate culture and a community contribution», Financial Times, 31 October, p.15.

Shiraz A. (1998), «Social Reporting», Australian CPA, November.

Stigson, B. (1997), «The Business Charter for Sustainable Development», in F. Dodds (ed.), The Way Forward: Beyond Agenda 21, Earthscan, London.

Stigson, B. (1999), «Business is shaping the agenda», in Tomorrow, Vol. IX, No. 4, July/August, p. 45.

Tesner S. (1999), The United Nations and Business: A Partnership Recovered, St. Martin's Press, New York.

The Concise Oxford English Dictionary (1999), Oxford University Press, Oxford.

ToBI (1997), NGO Perspective on Responsible Entrepreneurship

(www.coopamerica.org/isf/tobi/resp-entr/NGO\%20perspectives.html).

Thomson, B. (1998), Fair Trade - Frequently Asked Questions - FAQ, (www.web.net/fairtrade/who/ fair 2.html).

Tomorrow (1994), «In search of environmental excellence», Vol. IV, No. 4, July/August.

TRAC (1999), A Perilous Partnership: The United Nations Development Programme's Flirtation with Corporate Collaboration, Transnational Resource and Action Center, San Francisco.

Traidcraft (1998), Fair Trade and Ethical Trade: Distinct but Complementary (www.web.net/ fairtrade/other/briefing.html).

UNCTAD) (1996), Self-Regulation of Environmental Management: An Analysis of Guidelines Set by World Industry Associations for their Member Firms, UNCTAD, Geneva.

- (1998), World Investment Report 1998: Trends and Determinants, UNCTAD, Geneva.

- (1999), World Investment Report 1999: Foreign Direct Investment and the Challenge of Development, UNCTAD, Geneva.

- (2000), World Investment Report 2000: Cross-border Mergers and Acquisitions and Development, UNCTAD, Geneva.

- and SGS (1998), International Market Access Information: Horticultural Sector, United Nations, Geneva.

UNDP (1998), Human Development Report, 1998, Oxford University Press, Oxford.

- (1999a), The Global Sustainable Development Facility: Project Description, mimeo, UNDP, New York.

- (1999b), «Multinational corporations join discussions with UNDP to establish global sustainable development facility », UNDPFlash, Monday 15 March (www.undp.org/flash/fleng.htm).

UNEP (1994), Company Environmental Reporting: A Measure of the Progress of Business \& Industry Towards Sustainable Development, SustainAbility/UNEP Industry and Environment, London/Paris.

- (1998), «Voluntary initiatives for responsible entrepreneurship: A question and answer guide», Industry and Environment, Vol. 21, No.1-2, January-June, pp. 4-9.

- (2000), Voluntary Initiatives: Current Status, Lessons Learnt and Next Steps, UNEP, Paris

— and SustainAbility (1997), Engaging Stakeholders: The 1997 Benchmark Survey, SustainAbility, London 
United Nations (1999), Business and the UN: Partners in Sustainable Development, United Nations, New York.

UNRISD (1995), States of Disarray: The Social Effects of Globalization, UNRISD, Geneva, distributed by Earthscan, London.

- and UNA (1998), Business Responsibility for Environmental Protection in Developing Countries: Report of the International Workshop (Heredia, Costa Rica, 22-24 September 1997), UNRISD, Geneva.

UN Wire, «Business Humanitarian Forum: NGOs Criticize Ogata, Bellamy», United Nations Foundation UN Wire, 29 September

(www.unfoundation.org/unwire/archives/UNWIRE990929.cfm).

Utting, P. (1992), Economic Reform and Third-World Socialism: A Political Economy of Food Policy in Post-Revolutionary Societies, Macmillan, London.

Utting, P. (1993), Trees, People and Power: Social Dimensions of Deforestation and Forest Protection in Central America, Earthscan, London.

Utting, P. (2000a), Business Responsibility for Sustainable Development, OPG 2, UNRISD, Geneva.

Utting, P. (2000b), UN-Business Partnerships: Whose Agenda Counts?, paper presented at «Partnerships for Development or Privatization of the Multilateral System?» seminar, North-South Coalition, Oslo, Norway, 8 December, 2000.

Utting, P. (ed.) (forthcoming), The Greening of Business in the South: Rhetoric, Practice and Prospects.

von Moltke K. et al. (1998), Global Product Chains: Northern Consumers, Southern Producers and Sustainability, Environment and Trade 15, United Nations Environment Programme, Geneva.

Watts, P. and Lord Holme (1999), Corporate Social Responsibility: Meeting Changing Expectations, World Business Council for Sustainable Development, Geneva.

Welford, R. (1997), Hijacking Environmentalism: Corporate Responses to Sustainable Development, Earthscan, London.

Welford, R. and D. Jones (1996), «Beyond environmentalism and towards sustainable organization», in R. Welford (ed.) Corporate Environmental Management: Systems and Strategies, Earthscan, London.

West, K. (1995), «Ecolabels: The industrialization of environmental standards», The Ecologist, Vol. 25, No. 1, January/February, pp. 16-20.

Wild, A. (1998), A Review of Corporate Citizenship and Social Initiatives: Social Citizenship - What's Going On ... and Why?, Enterprise and Cooperatvie Development Department, ILO, Geneva.

Wood, D.J. (1991), «Social issues in management: Theory and research in corporate social performance», Journal of Management, Vol. 17, pp. 383-406.

World Bank (1998), World Development Report 1998, Oxford University Press, Oxford.

World Bank (1999), 1999 World Development Indicators, World Bank, Washington, DC.

WBCSD (1999), «Why is CSR climbing on the international agenda», Tomorrow, Vol. IX, No. 3, May/June.

WCED (1987), Our Common Future, Oxford University Press, Oxford/New York.

World Rainforest Movement (1999), Tree Plantations: Impacts and Struggles, World Rainforest Movement, Montevideo.

World Resources Institute (1998), World Resources Institute and General Motors Open Dialogue on Global Climate (www.icg.org/wri/press/wrigm-nr-html).

Zarrilli, S., V. Jha and R. Vossenaar (eds.) (1997), Eco-Labelling and International Trade, Macmillan, London. 